REVIEW ARTICLE OPEN

\title{
Review of nanomaterials-assisted ion exchange membranes for electromembrane desalination
}

\author{
Adetunji Alabi ${ }^{1}$, Ahmed AlHajaj', Levente Cseri ${ }^{2}$, Gyorgy Szekely ${ }^{2}$, Peter Budd ${ }^{3}$ and Linda Zou ${ }^{1}$
}

In order to address the increasing demand for fresh water due to accelerated social and economic growth in the world, water treatment technologies, such as desalination, have been rapidly developed in attempts to safeguard water security.

Electromembrane desalination processes, such as electrodialysis and membrane capacitive deionization, belong to a category of desalination technologies, which involve the removal of ions from ionic solutions with the use of electrically charged membranes termed ion exchange membranes. The challenges associated with ion exchange membranes have drawn the attention of many researchers, who have investigated various approaches to enhance their properties. The incorporation of nanomaterials is one of the popular approaches employed. Much research on nanomaterials incorporated ion exchange membranes was conducted for the purpose of fuel cell applications rather than electromembrane desalination. This review reports on the advances in nanomaterials incorporated ion exchange membranes applicable to desalination. The nanomaterials employed in ion exchange membranes fabrication include carbon nanotubes, graphene-based nanomaterials, silica, titanium (IV) oxide, aluminum oxide, zeolite, iron (III, III) oxide, zinc oxide, and silver. The aims of this article are to provide a snap shot of the current status of nanomaterials incorporation in ion exchange membranes, to assess the status of nanomaterials-facilitated ion exchange membranes research for electromembrane desalination, and to stimulate progress in this area.

npj Clean Water (2018)1:10; doi:10.1038/s41545-018-0009-7

\section{INTRODUCTION}

lon exchange membranes (IEMs) have attracted much interest from the academic and industrial fields, due to their potential applications in electromembrane processes ${ }^{1}$ which include: (1) water purification, e.g., desalination by electrodialysis (ED), desalination by membrane capacitive deionization (MCDI), and diffusion dialysis; (2) energy production, e.g., as fuel cells, and reverse electrodialysis; (3) energy storage e.g., flow batteries; and (4) the chlor-alkali process. Significant milestones in the advancement of IEMs are highlighted in the time line shown in Fig. 1a. In the last several decades, research activities led to many minor incremental improvements.

IEMs contain charged groups, affixed to the polymer backbone of the membrane material, which partially or totally prevent ions with the same charge from passing through the membrane. Membranes with fixed positively charged groups, termed anion exchange membranes (AEMs), preclude the passage of cations but permit the passage of anions. ${ }^{2,3}$ Membranes with fixed negatively charged groups, termed cation exchange membranes (CEMs), prevent the passage of anions but allow cations to pass through. ${ }^{2,3}$ Based on this mode of operation, electromembrane desalination was developed, as evidenced by electrodialysis (ED) desalination-which is the first large-scale industrial process to utilize IEMs. ${ }^{2}$ To date, ED has been the most widely researched and commercially adopted electromembrane desalination process. Therefore, the main focus in this review will be on ED.

A schematic overview of an ED desalination process is shown in Fig. 1b. A number of CEMs and AEMs are organized in an alternating fashion between an anode and a cathode, with an electrical potential applied between the electrodes. Each set of AEMs and CEMs makes up a cell pair. The IEMs used for ED desalination are required to have high performance in a number of properties, including ion exchange capacity (IEC), transport number, permselectivity, mechanical strength, thermal stability, and ionic conductivity. The range of values for some key IEMs properties for ED is shown in Table 1.

Details on IEMs properties and their characterization are treated elsewhere. ${ }^{4,5}$ The properties of IEMs primarily depend on: ${ }^{4,5}$ (1) the membrane material, which chiefly determines the mechanical, chemical, and thermal stability of IEMs; and (2) the type, concentration, and distribution of the ion exchange groups which determine the electrochemical properties of the IEMs and also happen to considerably influence the other IEMs properties. The electrochemical properties are the most significant properties in ED. ${ }^{5}$

The quest for developing IEMs with excellent properties is ongoing and many approaches have been attempted to synthesize robust IEMs suitable for different applications. Some of the methods adopted to create IEMs with enhanced properties include variation of functional groups, ${ }^{6}$ combination of polymers, ${ }^{7,8}$ adjustment of cross-link density, ${ }^{9}$ inclusion of additives, ${ }^{10}$ and surface modification. ${ }^{11}$

Incorporation of nanomaterials (NMs) into IEMs has also been investigated as a means of improving their properties. ${ }^{12,13}$ The majority of the cases where NMs were incorporated in IEMs are in the fuel cells research area, with fewer reports related to ED desalination. Nonetheless, the NMs-incorporated IEMs developed

\footnotetext{
${ }^{1}$ Civil Infrastructure and Environmental Engineering, Khalifa University, Masdar Campus, PO BOX 127788, Abu Dhabi, UAE; ${ }^{2}$ School of Chemical Engineering and Analytical Science, The University of Manchester, Manchester M13 9PL, UK and ${ }^{3}$ School of Chemistry, The University of Manchester, Manchester M13 9PL, UK

Correspondence: Linda Zou (lyuanzou@masdar.ac.ae)
}

Received: 3 September 2017 Revised: 04 February 2018 Accepted: 6 February 2018

Published online: 09 July 2018 
a

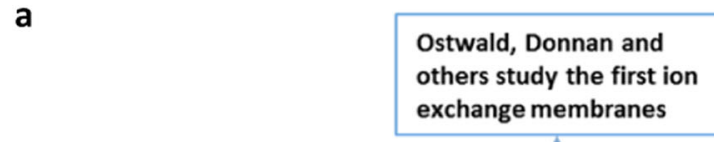

Ionics produces the reverse polarity process, a breakthrough in electrodialysis plant reliability

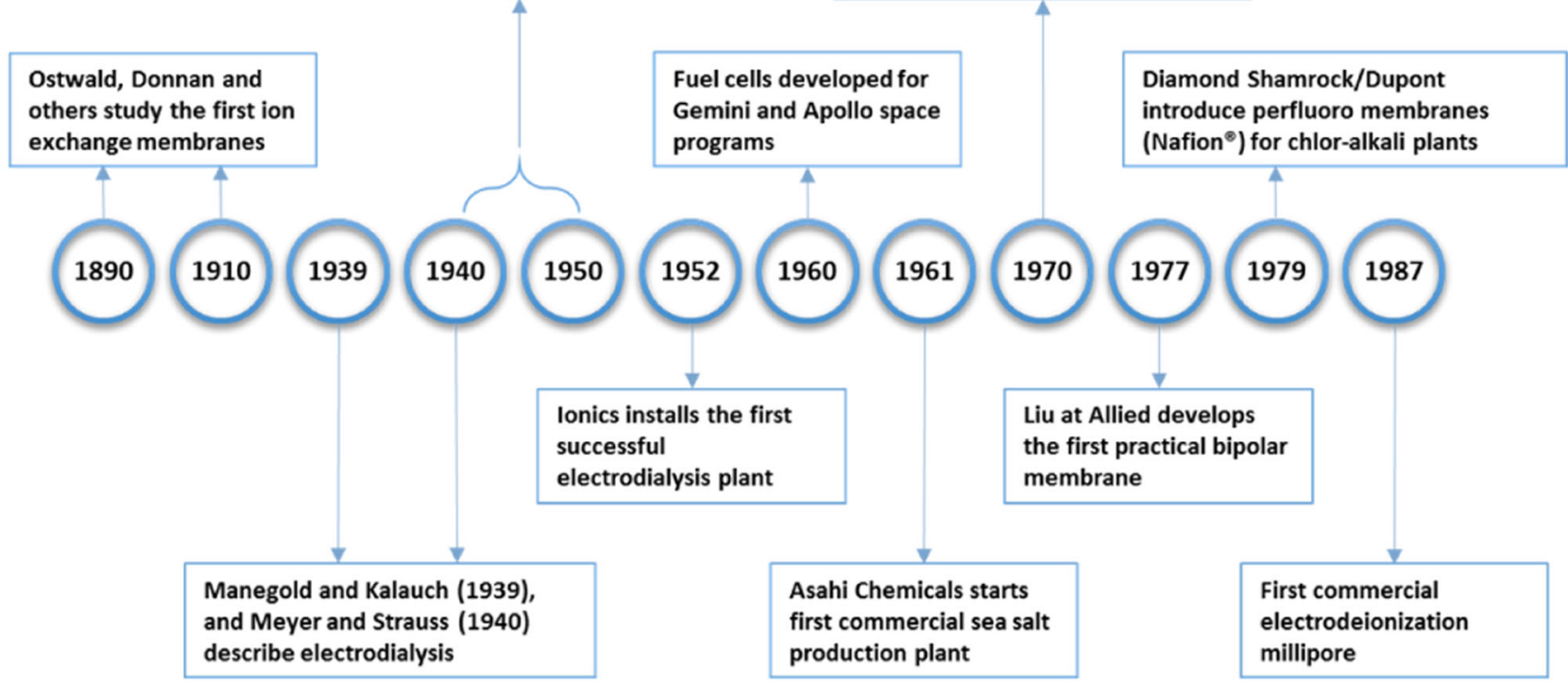

b

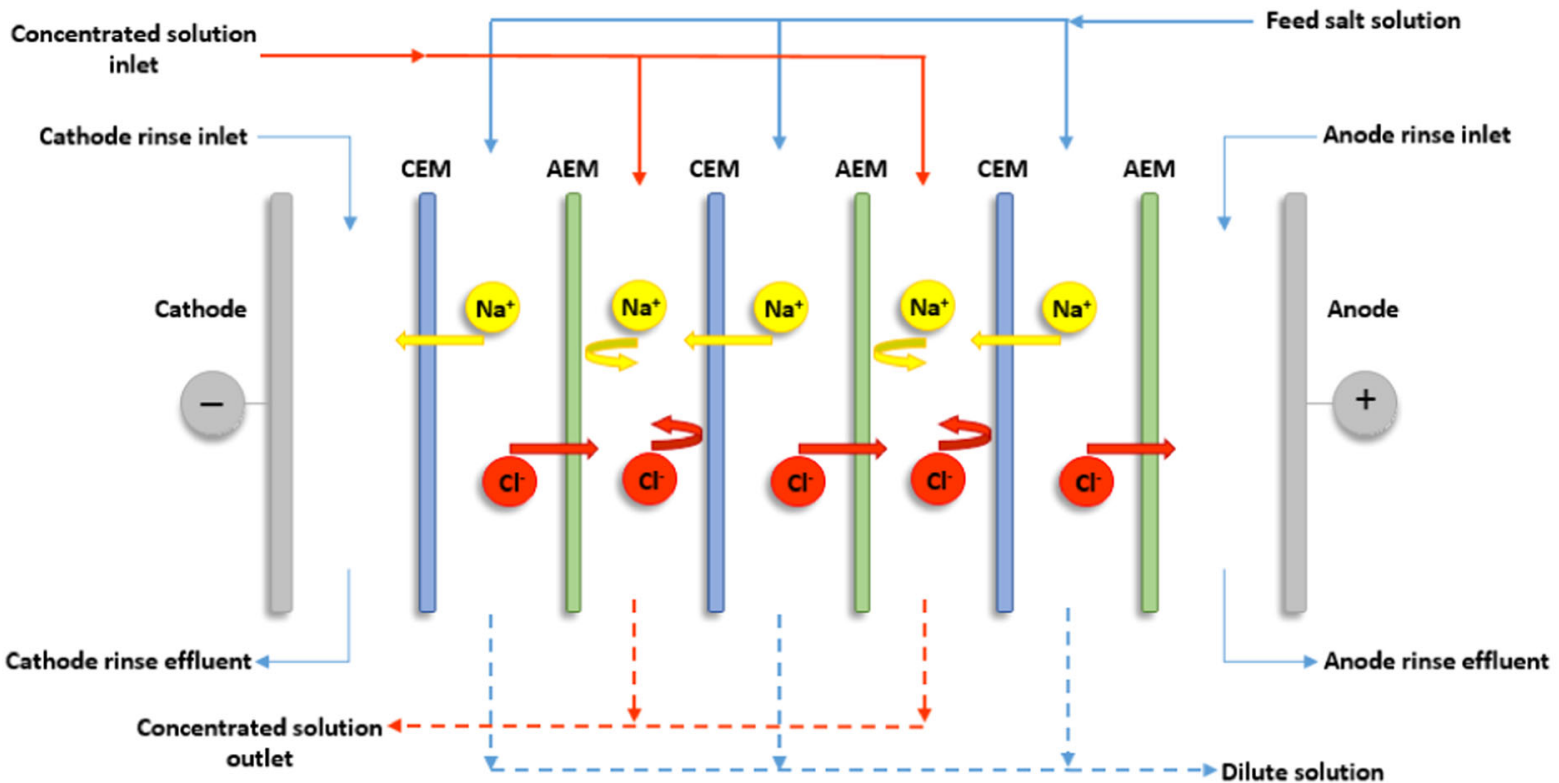

Fig. 1 Ion exchange membranes and electrodialysis. a Milestones in the development of IEMs processes. ${ }^{2} \mathbf{b}$ Schematic illustration of an ED process. Once an ionic solution (e.g., sodium chloride solution) is fed through the cell pairs, the anions (i.e., $\mathrm{Cl}^{-}$) migrate in the direction of the positively charged anode and the cations (i.e., $\mathrm{Na}^{+}$) migrate in the direction of the negatively charged cathode. The anions are able to pass through the AEMs but are restricted from passing through the CEMs. Likewise, the cations are allowed passage through the CEMs but do not have access through the AEMs. The eventual outcome of this process is that one segment of a cell pair experiences an increase in ionic concentration, while the adjacent segment experiences a decrease in ionic concentration. As a result, the formation of dilute and concentrated solutions is alternated between the segments, respectively. Figure in a adapted from ref. ${ }^{2}, \odot 2012$ Wiley

\begin{tabular}{|ll|}
\hline Table 1. Properties of commercial IEMs used for $\mathrm{ED}^{4,162}$ & \\
\hline IEMs property & Range \\
\hline IEC & $1-3 \mathrm{meq} / \mathrm{g}$ \\
Electrical resistance & $1-15 \Omega \mathrm{cm}^{2}$ \\
Transport number & $0.75-0.95$ \\
\hline
\end{tabular}

for fuel cells may also be suitable for desalination by ED. The major concern regarding their applications for ED is the potential toxicity of the NM, since the main objective of ED desalination is to produce fresh water from brackish water. Hence, any toxicity caused by the NMs should be taken into account. For example, utilizing iron-nickel oxide $\left(\mathrm{Fe}_{2} \mathrm{NiO}_{4}\right)$ nanoparticles in $I E M s^{14,15}$ for ED may be unsuitable since the toxicity of nickel could be a major concern in the fresh water supply. ${ }^{16,17}$

Details about the NMs used in IEMs, methods of incorporating the NMs into IEMs, functionalization of NMs, the benefits and 
drawbacks of incorporating the NMs into IEMs, the influence of NM shape and size, and their applicability to ED desalination are presented in the following sections of this review. Since there are other review articles and text books that cover the various topics on types of IEMs, ${ }^{18-20}$ preparation of IEMs, ${ }^{4,5,12,20-22}$ functionalizing polymeric materials for IEMs, ${ }^{18,20,23}$ characterization of IEMs, $4,5,19,20,24$ and $E D^{2-5,25-27}$ the detailed information on these topics will not be covered here.

\section{METHODS OF INCORPORATING NANOMATERIALS INTO ION EXCHANGE MEMBRANES}

Solution blending

The method of solution blending is based on the solubility of the polymer and a suitable solvent. A schematic description of the general procedure of the solution blending method is illustrated in Fig. 2.

Solution blending is by far the most frequently used technique in fabricating polymeric nanocomposites, ${ }^{28,29}$ and is thus commonly used in synthesizing NMs-assisted IEMs. It has the advantage of being straightforward, easily reproducible and thus appropriate for large-scale production. ${ }^{30}$ It is considered the most favorable option because of the availability of solvents that readily dissolve any polymer type. Some solvents, along with the NMs and polymers, used for incorporating NMs into IEMs are listed in Table 2. Among the solvents, the versatility of $N, N$-dimethylacetamide (DMAc) and $\mathrm{N}, \mathrm{N}$-dimethylformamide (DMF) is evident by the wide array of polymers they are used in conjunction with.

\section{In situ polymerization}

Although, similar to the solution blending method, in situ polymerization involves the use of monomers rather than preformed polymers. Basically, NMs or their precursors are dispersed in a liquid monomer or monomer solution, followed by polymerization. ${ }^{31}$ The polymerization is usually induced by the diffusion of an appropriate initiator or by applying heat or UV irradiation. The polymerization step is the distinction between in situ polymerization and solution blending. This extra step makes this method more costly and time consuming when compared with solution blending. As a result, it is seldom used for the incorporation of NMs into IEMs.

\section{Melt mixing}

Melt mixing involves the dispersion of NMs in a molten polymer matrix. Techniques such as extrusion and injection molding are used to mix a thermoplastic polymer with NMs at elevated temperatures. $^{32}$ As a result, the polymer chains become intercalated to form polymeric nanocomposites. The method of melt mixing does not require any solvent. However, a disadvantage of this technique is its unsuitability for thermosetting polymers. Furthermore, the melt mixing method can be affected by some undesired outcomes, which include: decomposition of the

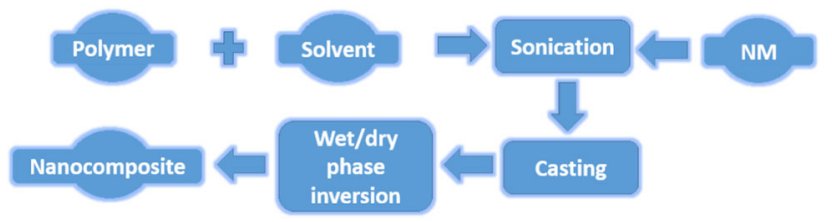

Fig. 2 General schematic representation of solution blending method of NM incorporation in IEMs. The polymer is dissolved in a solvent, followed by addition of the NMs. Hereafter, the solution is thoroughly mixed (usually via sonication or stirring) to ensure a uniform dispersion of the NM in the polymer. Afterwards, the solvent is removed (by phase inversion) and the NMs are rearranged and embedded in the polymer to form mixed matrix membranes polymer; inadequate NMs dispersion; and degradation of the surface modifier. ${ }^{13}$

In situ sol-gel

The in situ sol-gel technique involves mixing a polymer with a NM precursor-such as tetraethoxysilane (TEOS) for silica-followed by hydrolysis and polycondensation of the precursor. ${ }^{33}$ The in situ sol-gel technique is used for incorporating only NMs which have precursors e.g., silica and $\mathrm{TiO}_{2}$, as such its applicability is limited to a few NMs. Moreover, the hydrolysis and polycondensation step make it more costly and time consuming in comparison to the solution blending technique. A more desirable alternative would be using solution blending technique with already fabricated NMs.

\section{THE ROLE OF NMS IN IEMS: PROPOSED MECHANISMS}

Despite the widespread utilization of NMs in IEMs, there is limited understanding of the mechanism(s) by which the improvements are made. Different mechanisms have been provided to explain the way in which NMs improve the electrochemical properties of IEMs.

Many research works have attributed the improved IEMs properties to the presence of functionalized NMs which provide additional ionic groups for ion exchange. ${ }^{34-37}$ This hypotheses of the provision of additional functional groups for ion exchange could be valid for a specific case i.e., where the degree of functionalization of the NMs is high and the quantity of functionalized NMs in the nanocomposite IEMs is considerably high enough to produce a significant increase in the IEC by virtue of the additional concentration of the ionic groups. This explanation is however not satisfactory for cases where the NMs are not functionalized. There are many instances where addition of non-functionalized NMs resulted in improvements in the IEC of IEMs. ${ }^{31,37,38}$ Therefore, we are led to conclude that there must be some other mechanism(s) responsible for the improved properties of nanocomposite IEMs.

There is another mechanism, which we term ionic cluster dispersion, which asserts that the incorporation of NMs facilitates the creation of interconnected ion conducting pathways within the membrane matrix of nanocomposite IEMs. ${ }^{39-42}$ It has been observed that the addition of NMs results in better distribution of ionic clusters in nanocomposite IEMs ${ }^{43,44}$ (see Fig. 3). This improved dispersion of ionic clusters results in formation of more ion conducting channels which provide more pathways for ion transport. A schematic illustration of the ionic cluster dispersion mechanism (ICDM) is given in Fig. 4. The ionic cluster dispersion mechanism (ICDM) seems to be the primary way in which NMs improve the properties of IEMs. In addition, it provides a reasonable explanation for increments in IEC for cases where non-functionalized NMs are employed in the nanocomposite IEMs. Apart from this primary effect in which NMs improve the properties of IEMs, additionally, it provides an incremental improvement in IEC for cases where functionalized NMs are used in the nanocomposite IEMs. In the latter case, the reported increase in IEC could be due to the increased exposure/availability of the ionic functional groups for ion exchange due to the increased dispersion of the ionic clusters in the polymer matrix.

For functionalized NMs, it can be assumed that an interplay between both of the mechanisms results in the observed improvements in nanocomposite IEMs, whereas for nonfunctionalized NMs only the latter mechanism dominates.

\section{NANOMATERIALS USED IN ION EXCHANGE MEMBRANES}

Notable results with different NMs have been reported in numerous works, the findings of which are expounded in each NMs subsection below. The detailed summaries of NMs 
Table 2. Examples of solvents, as well as nanomaterials and polymers used in solution blending

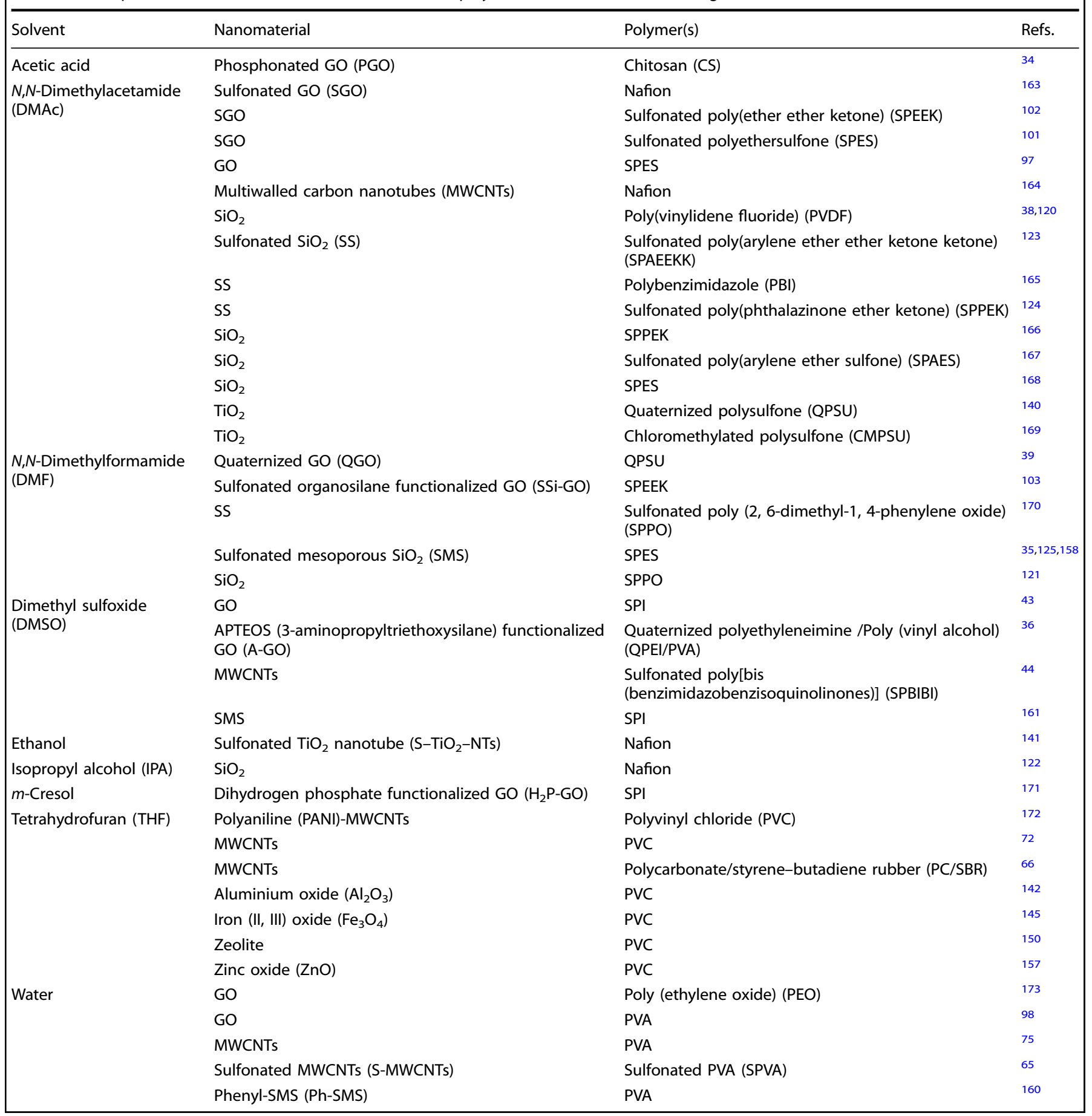

incorporated IEMs with properties relevant to ED are provided in Tables 3-6.

Due to the diverse test conditions used in the research works, the direct comparison of the properties of the nanocomposite IEMs across the different research works reported will be difficult and misleading. The values of these properties vary significantly with the test conditions, and as such any comparisons made between the different research works will not be reliable. For example, the transport number, and ionic conductivity of IEMs depend on the type of electrolytes and their concentrations in the test solution. ${ }^{5}$ Similarly, the ionic conductivity results also vary depending on the measurement method used. ${ }^{4}$ The only property of the IEMs that can be compared irrespective of test conditions is the ion exchange capacity (IEC). This is because the IEC is an intrinsic property of the membrane which is determined by acid base titration. Hence, we make a recommendation for studies to be carried out under similar conditions so that reliable comparisons of the properties can be made between nanocomposite IEMs across different research works.

Carbon nanotubes (CNTs)

CNTs are practically one-dimensional hollow cylindrical tubes, made up of atom thick layers of carbon atoms, having a diameter measuring on the nanometer scale. ${ }^{45-47}$ CNTs are usually classified 

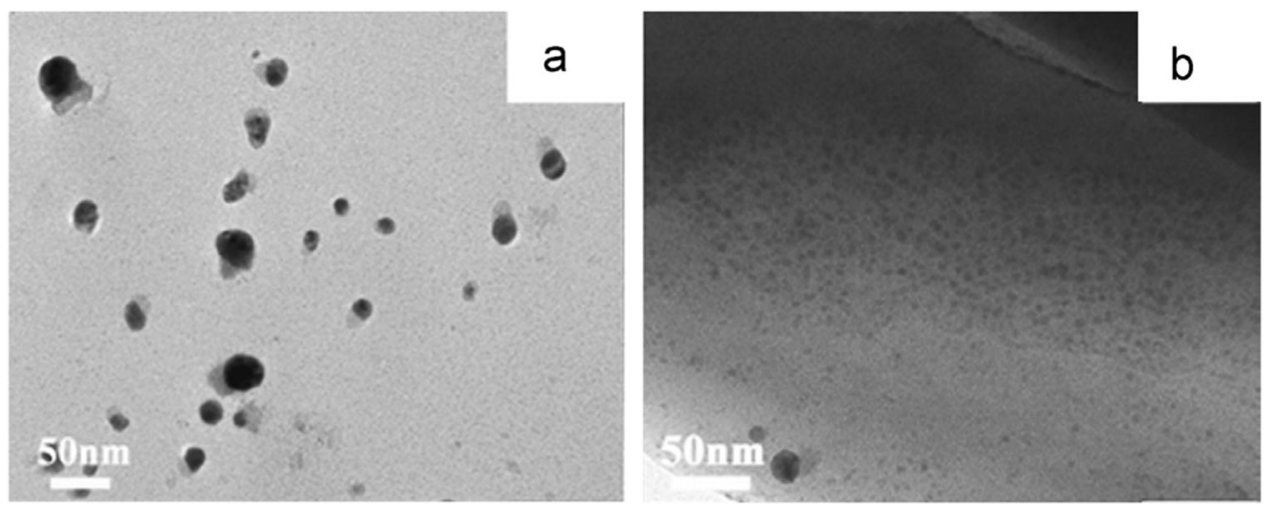

Fig. 3 TEM micrographs of sulfonated polyimide (SPI) based CEMs showing the ionic clusters-identified by the dark-silver-stained roundshaped regions. a Pristine SPI with bigger ionic clusters. b SPI incorporated with GO. The introduction of GO into the SPI membrane matrix results in further dispersion of the ionic clusters thus reducing the distance between ionic clusters, increasing the surface area of the available ionic groups for ion exchange, and creating additional channels for ionic transport. ${ }^{43}$ Figures reproduced with permission from ref. ${ }^{43}$, $\odot 2014$ Elsevier

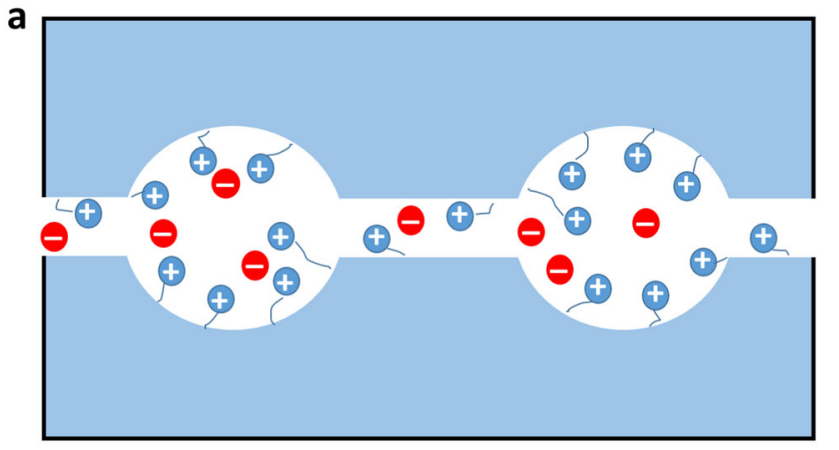

b

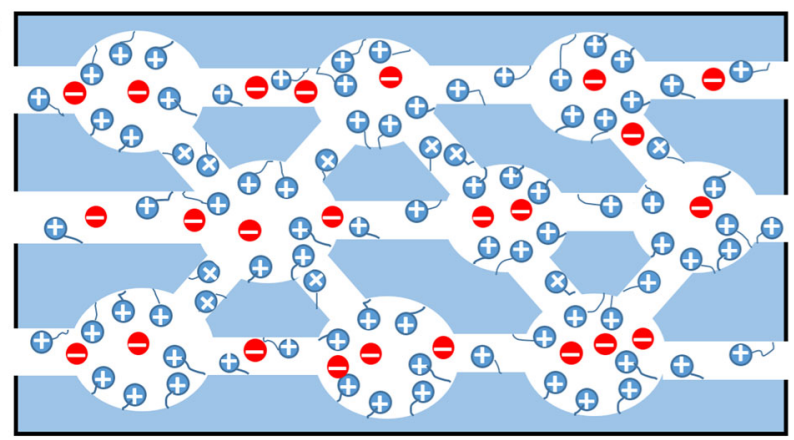

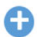

Fixed charges

Counterions

Fig. 4 Schematic illustration of the ionic cluster dispersion mechanism in AEMs. a Pristine AEMs. b AEMs incorporated with NMs. The clusters (shown in $\mathbf{a}, \mathbf{b}$ ) are connected by ion conducting channels which creates a network for the migration of the oppositely charged ionic groups (counterions). In b the incorporation of NMs facilitates the dispersion of the ionic clusters and consequently creates more interconnected ion conducting channels compared to a. Furthermore, the distance between the ionic clusters is reduced. These changes ensure higher exposure of the fixed charges for ion exchange, and also promote the transport of counterions through the additional and shorter conducting channels of the AEMs

as either single-walled carbon nanotubes (SWCNTs) ${ }^{46,48,49}$ or multi-walled carbon nanotubes (MWCNTs). ${ }^{49,50}$ SWCNTs are seamless cylinders, comprising a single graphene sheet, with diameters ranging from 0.4 to $3 \mathrm{~nm}$. MWCNTs consist of concentric rolls of graphene sheets. Since the discovery of CNTs, ${ }^{50}$ they have drawn a considerable amount of attention due to their fascinating electrical ${ }^{51-53}$ and mechanical ${ }^{54-59}$ properties. CNTs have proven to be very versatile nanomaterials and thus have numerous applications such as high-strength composites, energy storage and energy conversion devices, sensors, field emission displays and radiation sources, hydrogen storage media, and nanometer-sized semiconductor devices, probes and interconnects, ${ }^{60-62}$ to mention a few.

Of particular interest is the application of CNTs in IEMs nanocomposites. In addition to the aforementioned characteristics, the high aspect ratio and high-surface area of CNTs make them suitable candidates as reinforcements in polymer nanocomposites. ${ }^{63,64}$ These same properties also enable CNTs to form ion conducting paths within a membrane matrix. ${ }^{65}$ A very good example is shown for polycarbonate/styrene-butadiene rubber (PC/SBR) CEMs embedded with MWCNTs, which displayed enhanced CEMs properties in comparison to their prisitne counterpart. ${ }^{66}$ Improvements were noted in membrane potential, surface charge density, permselectivity, and transport number. Furthermore, superior ionic permeability, ion flux, ionic conductivity, current efficiency, energy consumption and thermal stability were also observed.

The fabrication of polymer nanocomposite membranes with homogeneously dispersed CNTs is contingent on strong interfacial bonding between the CNTs and the polymer matrix. ${ }^{22}$ Despite the excellent properties of CNTs, it is challenging to attain a homogeneous dispersion of CNTs in many solvents. CNTs are inclined to aggregate into clusters of various dimensions, which can tremendously lower their dispersibility and ionic conductivity. ${ }^{67,68}$ A more uniform dispersion can be achieved by improving the intermolecular interactions between the MWCNTs and polymer substrate. Selecting a polymer substrate with the appropriate group can augment the interaction. Along this line, a remarkable dispersion of MWCNTs was demonstrated in a sulfonated poly[bis(benzimidazobenzisoquinolinones)] (SPBIBI) cast solution which was credited to the pi-pi interactions between the MWCNTs sidewalls and the pyridinone rings of sulfonated poly [bis(benzimidazobenzisoquinolinones)] (SPBIBI). ${ }^{44}$ Further evidence of improved dispersion was shown by morphological studies which revealed the formation of smaller, denser and more uniform ionic clusters as the MWCNTs content increased in the SPBIBI/MWCNTs CEMs (Fig. 5). The MWCNTs modified SPBIBI CEMs showed greater ionic conductivity, and mechanical strength compared to the unmodified SPBIBI membranes.

Functionalization of CNTs is sometimes performed in order to ensure uniform dispersion in the membrane matrix and improved 

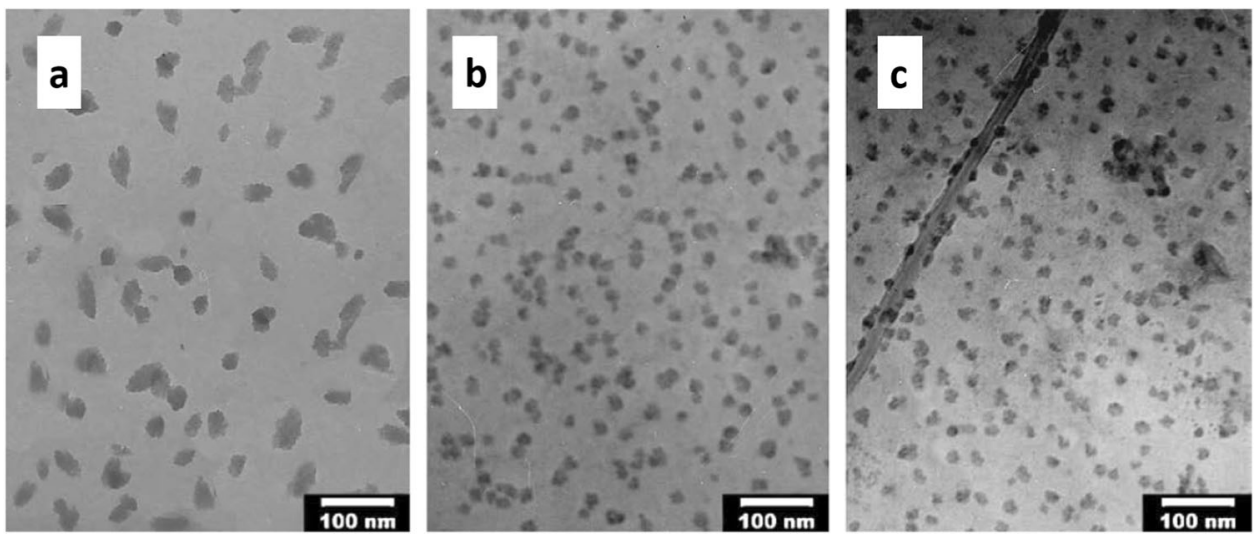

Fig. 5 TEM image showing ionic clusters in sulfonated poly [bis(benzimidazobenzisoquinolinones)] (SPBIBI) based CEMs. a Pure SPBIBI IEMs with bigger ionic clusters. b, c SPBIBI/MWCNTs ( 0.05 wt. \% NM content) and SPBIBI/MWCNTs ( 1 wt. \% NMs content). The incorporation of MWCNTs create smaller and more dispersed ionic clusters, therefore improving the electrochemical properties of the IEMs. ${ }^{44}$ Figures reproduced with permission from ref. ${ }^{44}$, ๔ 2009 Elsevier

a
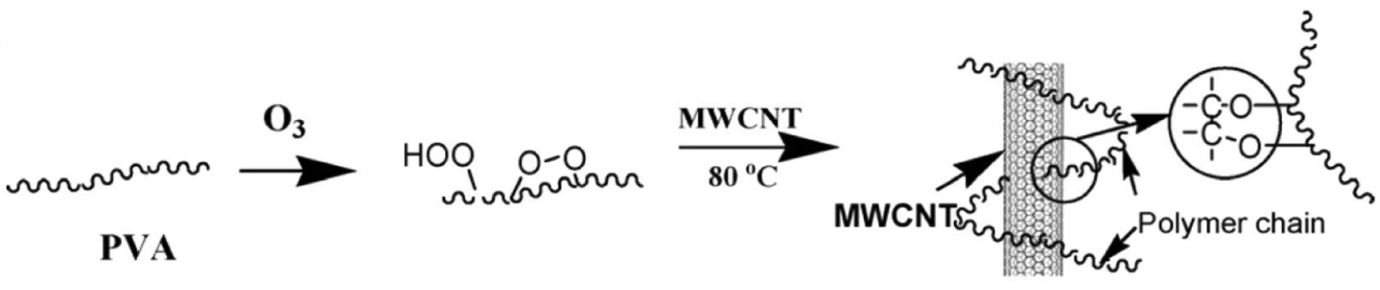

b
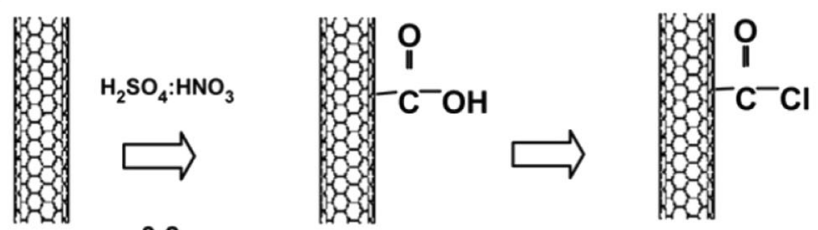

MWCNT-PVA

Raw CNT

$3: 2$

$\mathrm{SOCl}_{2}$

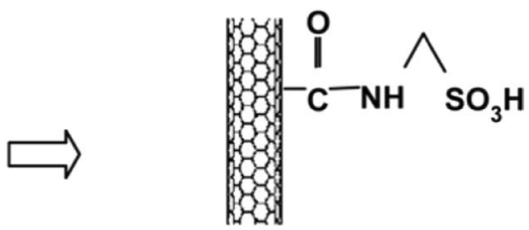

Fig. 6 Some methods of functionalization of CNTs. a Grafting of poly (vinyl alcohol) (PVA) onto MWCNT via ozonization of PVA. Ozonation is a useful method of chemically attaching polymers to NMs. A solution of PVA is purged with ozone gas to generate radicals on the chains of the PVA. These radicals on the PVA chains then enable the chemical binding of the PVA onto the MWCNTs. ${ }^{75}$ b Schematic representation of synthesis of sulfonated MWCNTs (S-MWCNTs) through a series of reactions with a mixture of $\mathrm{H}_{2} \mathrm{SO}_{4}$ and $\mathrm{HNO}_{3}(3: 1$ by volume \%); Thionyl Chloride $\left(\mathrm{SOCl}_{2}\right)$; and aminomethanesulfonic acid. ${ }^{65}$ Figures reproduced with permission from a ref. ${ }^{75}$, $\odot 2011$ Elsevier; $\mathbf{b}$ ref. ${ }^{65}$, 2011 Elsevier

adhesion of CNTs to the polymer. ${ }^{69,70}$ Moreover, depending on the functional group, functionalization could ensure additional ion exchange sites are present in the nanocomposite membrane to boost ion exchange. ${ }^{71}$ Some routes for functionalizing CNTs are shown in Fig. 6. SEM micrographs (Fig. 7) demonstrated better dispersion of sulfonated MWCNTs (S-MWCNTs) (as against pure MWCNTs) in sulfonated poly(vinyl alcohol) (SPVA) based CEMs. ${ }^{65}$ The homogeneous dispersion was attributed to improved interactions between the S-MWCNTs and the membrane matrix. In adddition, enhancements in the IEC, mechanical strength, ionic conductivity, and thermal stability of the modified AEMs were recorded in comparison to the pristine AEMs. Carboxylic funtionalized MWCNTs (COOH-MWCNTs) have been utilized in IEMs nanocomposites with reported success. Polyvinyl chloride (PVC)-based CEMs incorporated with $\mathrm{COOH}-M W C N T s$ exhibited higher ionic conductivity, thermal stability, membrane potential, ion flux and ionic permeability. ${ }^{72}$ One approach went a step further in modifying MWCNTs. With the aid of a magnetron sputtering technique, copper $(\mathrm{Cu})$ nanolayers were coated on $\mathrm{COOH}-M W C N T s{ }^{73}$ This copper-coated COOH-MWCNTs $(\mathrm{Cu}-\mathrm{COOH}-$ MWCNTs) was eventually incorporated into PVC based CEMs by solution blending. In comparison to the prisitne membrane, these modified CEMs demonstrated improved membrane potential, permselectivity, transport number, and mechanical strength, ionic permeability, ion flux, and ionic conductivity. Ozonation of polymers has been shown to produce organic peroxide groups which generate radicals when subjected to heat. ${ }^{74}$ These radicals enable the reaction of ozonized polymer chains with the sidewalls of CNTs, ${ }^{70}$ hence providing a way of modifying CNTs with nonreactive polymer chains. Such a technique was adopted in grafting poly(vinyl alcohol) (PVA) onto MWCNTs, followed by incorporating the resultant modified MWCNTs into poly(vinyl alcohol) (PVA) based AEMs. ${ }^{75}$ Higher ionic conductivity measurements were noted for the PVA/PVA-MWCNT AEMs in comparison to the plain PVA AEMs.

\section{Graphene-based nanomaterials}

Graphene and graphene-based NMs, such as graphene oxide (GO) and reduced graphene oxide ( $\mathrm{rGO}$ ), have received considerable interest for numerous applications due to the unique properties of graphene. ${ }^{76,77}$ Graphene is a flat monolayer of carbon atoms tightly arranged into a $2 \mathrm{D}$ honeycomb lattice, ${ }^{76}$ and is the basic structural unit of carbon allotropes, such as CNTs, graphite, and 

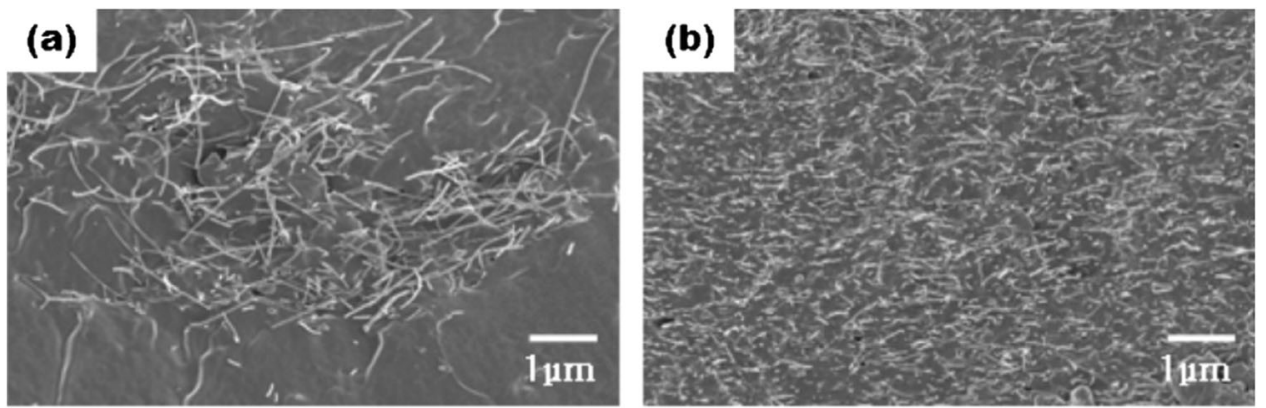

Fig. 7 SEM micrographs of sulfonated poly(vinyl alcohol) (SPVA) based ion exchange membranes. a Agglomeration of pure MWCNTs in the membrane. $\mathbf{b}$ Homogeneous dispersion of sulfonated MWCNTs (S-MWCNTs) in the membrane. ${ }^{65}$ Figures reproduced with permission from ref. 65, 2011 Elsevier

fullerenes. The exceptionally intriguing properties of graphene (which include high mechanical strength, ${ }^{78,79}$ high-electrical conductivity, ${ }^{80-82}$ high-thermal conductivity, ${ }^{83,84}$ and large specific surface area ${ }^{85-87}$ ) make graphene and graphene-based NMs (see properties in Table 7) very attractive candidates for applications such as biomedicals, ${ }^{88}$ supercapacitors, ${ }^{89}$ environmental, ${ }^{90}$ and energy production and storage. ${ }^{91}$ Research efforts have been devoted to modifying IEMs with graphene-based NMs in order to improve the performance of the composite IEMs. The enhancements associated with the introduction of graphene-based NMs into IEMs matrices are described in the subsection that follows, with special focus on parameters of relevance to ED desalination. Also, multiple routes to prepare graphene-based NMs-reinforced nanocomposite IEMs and the outcome of the modified IEMs towards superior performance are elucidated. A detailed summary of IEMs incorporated with graphene-based NMs is also provided in Table 3.

Plain graphene oxide in ion exchange membranes. GO is an oxidized form of graphene with the presence of oxygen functional groups (such as hydroxyl, epoxy, carbonyl, and carboxyl) in the carbon lattice. GO can be fabricated at low cost by chemical oxidation of graphite to graphite oxide followed by exfoliation via ultrasonication. $^{92}$ The low-production cost of GO makes it a favorable approach to synthesize graphene-based materials. Despite being a less costly option for producing exfoliated graphene sheets, the oxidation of graphite to $\mathrm{GO}$ tremendously lowers the physicochemical properties due to the high-defect density introduced in the carbon structure. ${ }^{93,94}$ The benefit, however, is that the oxygen functional groups endow GO with hydrophilic capabilities, consequently enabling $\mathrm{GO}$ to form stable suspensions in aqueous media. GO is highly favored as a building block for graphene-based materials. ${ }^{92,95,96}$

A significant consideration when fabricating IEMs incorporated with nanofillers is the dispersion of the nanofillers in the polymer matrix. Due to the more dispersible nature of GO in most solvents, it is the most widely used form of graphene-based NMs in IEMs. Improvements in the electrochemical properties and ED performance have been demonstrated in different studies. Among such studies, GO was shown to endow sulfonated polyethersulfone (SPES) based AEMs with higher ionic conductivity, transport number, and ionic flux in comparison to pure sulfonated polyethersulfone (SPES) AEMs. ${ }^{97}$ Most importantly, improvements were observed in the energy consumption and current efficiency during ED trials. In another study, poly(vinyl alcohol) (PVA) based AEMs modified by GO showed enhancements in ionic conductivity and mechanical strength compared to unmodified poly(vinyl alcohol) (PVA). ${ }^{98}$

Embedding of GO into IEMs is performed by the solution blending technique. However, there are other techniques reported in literature wherein $\mathrm{GO}$ is merely applied to the surface layer of the IEM. ${ }^{99,100}$ In these cases, the ensuing IEMs showed better IEC values than the unaltered IEMs. Despite the favorable results, a few concerns arise and need to be addressed-such as the homogeneity of the GO layer across the IEMs surface, the stability of the GO layer under turbulent conditions, and whether the GO layer is sufficient on its own to boost the performance of the entire IEMs. More tests are required to ascertain the genuineness and extent of these concerns.

Functionalized graphene oxide in ion exchange membranes. The oxygen groups in the carbon lattice allow GO to be modified by chemical reactions to introduce additional functional groups, which assist in boosting the IEMs properties even further. As mentioned earlier, functionalization serves to improve the dispersion of NMs in solvents and casting solutions, and could also provide additional functional groups for ion exchange (if the functionalization is ionic). Some routes adopted to functionalize GO for use in IEMs are shown in Fig. 8. Not surprisingly, the IEMs incorporated with functionalized GO have shown noteworthy improvements. Recently, quaternized polyethyleneimine/poly (vinyl alcohol) (QPEI/PVA) AEMs were modified with APTEOS (3aminopropyltriethoxysilane) functionalized GO (A-GO). ${ }^{36} \mathrm{Com}-$ parative tests conducted to assess the performance of the A-GO modified QPEI/PVA against the pure QPEI/PVA AEMs showed greater IEC, transport number, ionic conductivity, water uptake, mechanical strength, and thermal stability for the modified AEM. Additionally, the energy consumption and current efficiency during ED were observed to be much improved for the modified AEMs in compariosn to the pristine QPEI/PVA. In another work, A$G O$ was further functionalized via an epoxide ring opening reaction using glycidyltrimethylammonium chloride (GDTMAC) to yield quaternized GO (QGO). Tests revealed that the AEMs incorporated with the quaternized GO (QGO) outperformed their pristine counterparts with regards to IEC, water uptake, ionic conductivity and mechanical strength. Another good example presented the benefits of sulfonated GO (SGO) in IEMs. ${ }^{101}$ The SGO modified sulfonated polyethersulfone (SPES) CEMs demonstrated superior ionic conductivity, ionic flux, swelling, IEC, mechanical strength, and energy consumption and current efficiency during $E D$, when compared to the pristine sulfonated polyethersulfone (SPES). Validation of the functionalization of $\mathrm{GO}$ has been displayed in some research works wherein different kinds of functionalized GO were shown to have more pronounced effects on IEMs than plain GO. ${ }^{34,102,103}$ These IEMs incorporated with functionalized GO demonstrated superior IEM properties in comparison to the plain GO incorporated counterparts and the virgin IEMs.

Reduced graphene oxide in ion exchange membranes. rGO presents another strategy for enhancing IEMs with carbonaceous nanofillers. The reduction of GO can be accomplished through chemical reducing agents, photoreduction, thermal annealing, or microwave-assisted reduction. ${ }^{104,105}$ The chemical structure of 


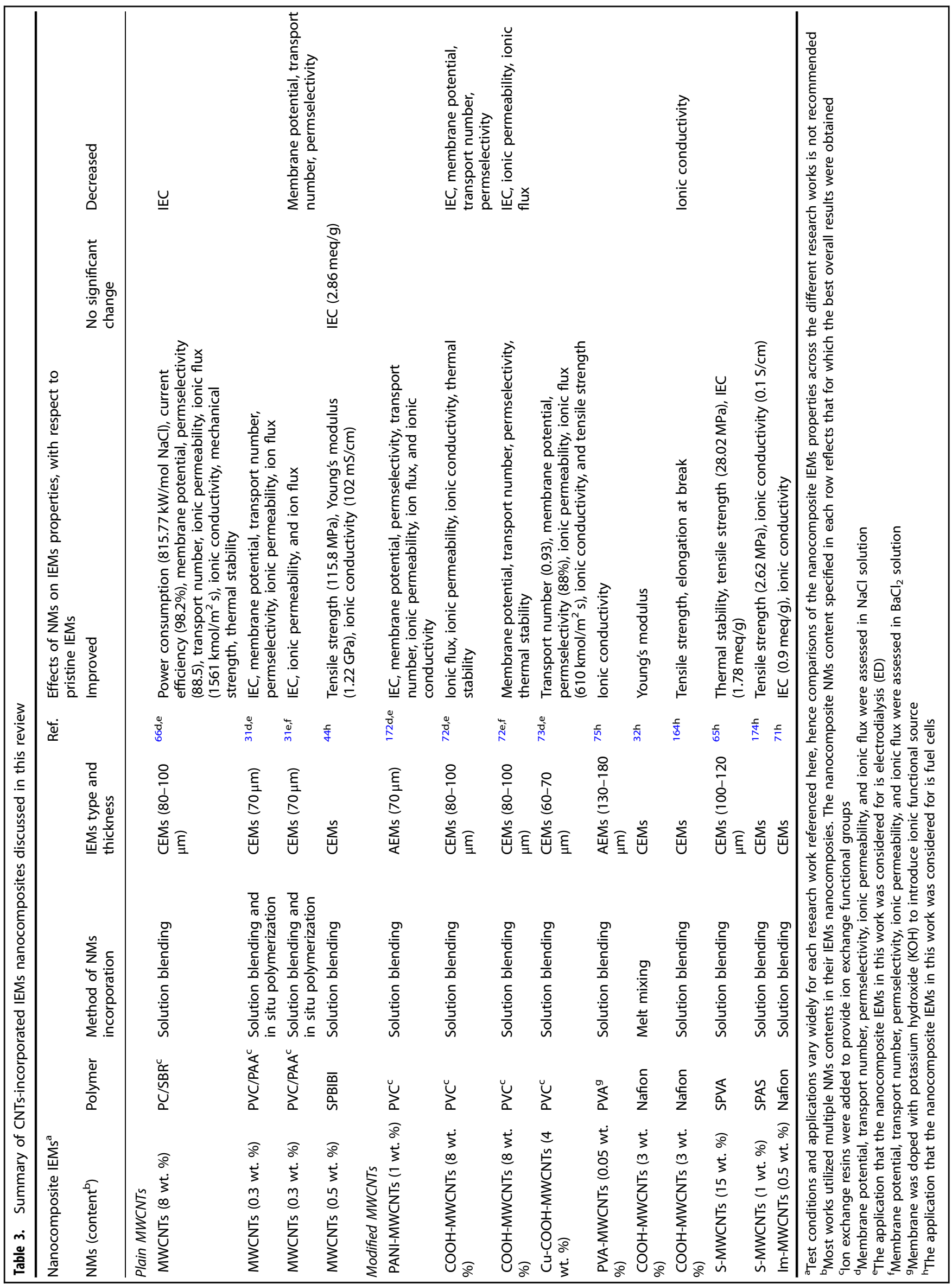




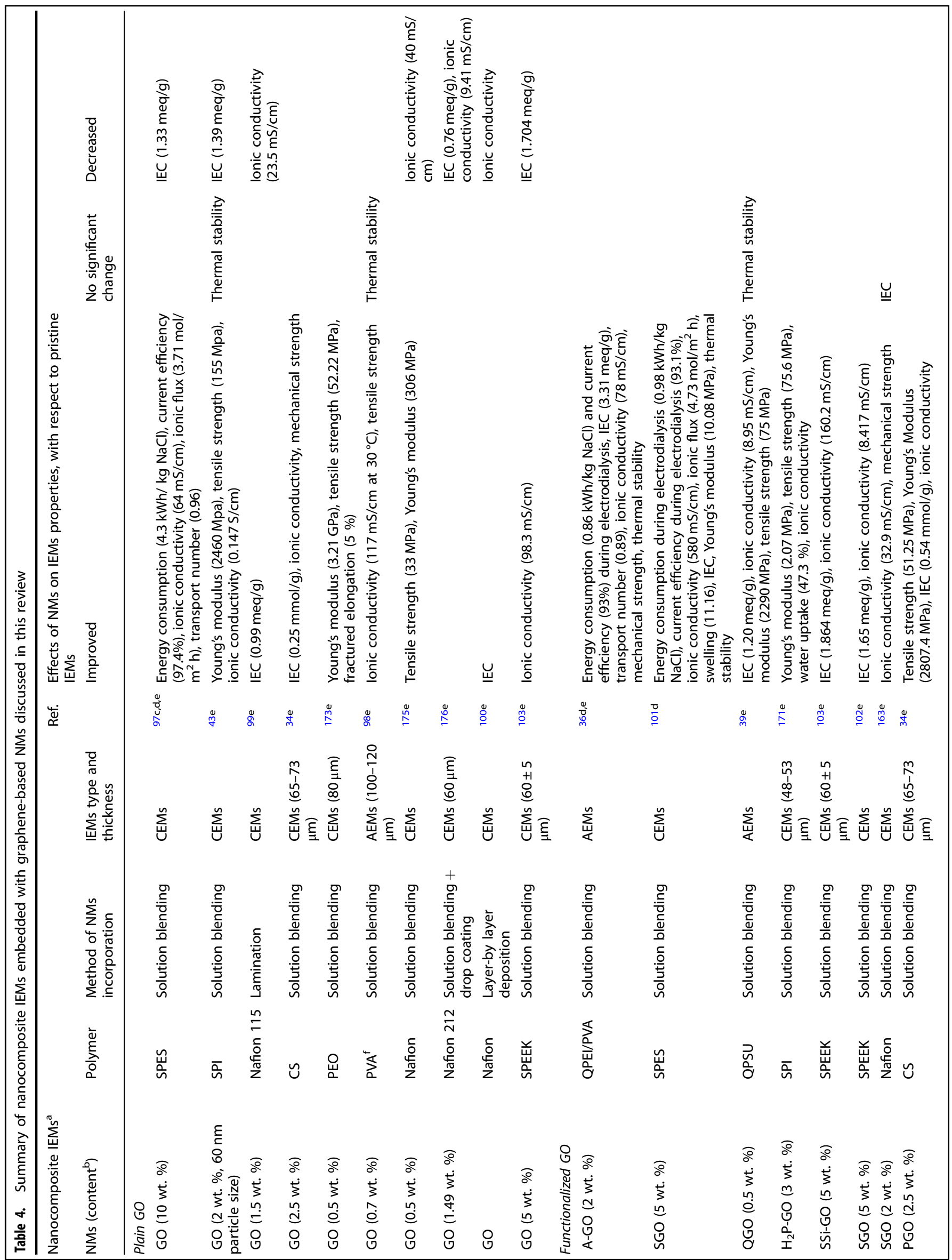


rGO is characterized by carbon vacancies, residual oxygen functional groups, and clustered pentagons and heptagons carbon structures. ${ }^{106,107}$ Moreover, rGO is hydrophobic due to the reduction of polar functional groups on its surface. ${ }^{105}$ Regardless, rGO (in comparison to GO) possesses properties that approach that of pristine graphene. Notable improvements in IEC and ionic conductivity were observed for poly(vinylidene fluoride)/ polyaniline (PVDF/PANI)-based AEMs upon incorporation with rGO. ${ }^{108}$ One research work established sulfonated rGO (S-rGO) to be more potent than plain $\mathrm{rGO}$ in boosting the properties of IEMs. ${ }^{109}$ Particularly, the S-rGO-incorporated IEMs displayed superior ionic conductivity and mechanical strength.

Silica $\left(\mathrm{SiO}_{2}\right)$ nanoparticles

Silica NPs are one of the widely investigated oxide nanoparticle types. Methods of synthesizing silica NPs include sol-gel, ${ }^{110,111}$ and flame synthesis. ${ }^{111,112}$ The sol-gel technique is commonly used due to a high level of control over the particle size, size distribution and morphology. ${ }^{11,113}$ By virtue of their simple fabrication, chemical inertness, and relatively affordable precursors, silica NPs have received substantial considerations for various applications, such as in biomedical applications, ${ }^{114-116}$ catalytic applications, ${ }^{117,118}$ and fillers in polymer nanocomposites. ${ }^{13,119}$ This is motivated by the increased desire for materials with improved thermal, mechanical, physical, and chemical properties.

Silica NPs have also been widely used in fabricating nanocomposite IEMs with a number of successful outcomes. One of such cases reported an increasing trend of IEC, transport number, permselectivity, fixed charge concentration, and ionic conductivity values with increments in $\mathrm{SiO}_{2}$ content of poly(vinylidene fluoride) (PVDF) based nanocomposite AEMs. ${ }^{120}$ In another work, electrochemical test results showed the IEC, porosity, permselectivity, fixed charge concentration, ionic conductivity, and thermal stability to improve with increasing $\mathrm{SiO}_{2} \mathrm{NPs}$ fraction. ${ }^{38} \mathrm{ED}$ tests carried out on poly(vinylidene fluoride) (PVDF)-based AEMs and CEMs embedded with $\mathrm{SiO}_{2}$ ascertained the modified membranes to be superior to the unmodified versions as displayed by the improved IEC, salt ions $\left(\mathrm{Na}^{+}, \mathrm{Ca}^{2+}, \mathrm{Cl}^{-}\right.$, and $\left.\mathrm{SO}_{4}{ }^{2-}\right)$ removal efficiency, and limiting current density. ${ }^{37}$ Silica NPs are usually employed as reinforcements to improve thermal and mechanical stability. In some cases, improvements in thermal stability and mechanical strength come; however, at the expense of the IEC hence causing a reduction in the fixed charge concentration of the nanocomposite IEMs. ${ }^{121}$ An approach for overcoming the suppression of the IEC could be the inclusion of ionic surfactants into the fabricated IEMs nanocomposite. ${ }^{122}$ The anionic surfactant not only contributes additional functional groups to the IEMs, but also facilitates the dispersion of the $\mathrm{SiO}_{2}$ in the nanocomposite.

When functionalized, silica NPs are capable of further enhancing the performance of IEMs. Sulfonation has been the most implemented type of functionalization (see Fig. 9a, b for examples of some schemes for sulfonating silica used in IEMs). Sulfonated poly(arylene ether ether ketone ketone) (SPAEEKK)-based CEMs incorporated with sulfonated $\mathrm{SiO}_{2}$ (SS) displayed higher fixed ion concentration, ionic conductivity, and thermal stability in comparison to both the plain $\mathrm{SiO}_{2}$ embedded SPAEEKK membranes and their unmodified counterparts. ${ }^{123}$ Comparitive studies between SS and $\mathrm{SiO}_{2}$ demonstrated that both $\mathrm{SS}$ and plain $\mathrm{SiO}_{2}$ improved the thermal stability of sulfonated poly(phthalazinone ether ketone) (SPPEK) based CEMs, whereas only SS improved the ionic conductivity of the SPPEK CEMs. ${ }^{124}$ Tests to evaluate the ED performance of sulfonated polyethersulfone/sulfonated mesoporous silicon (IV) oxide (SPES/SMS) nanocomposite CEMs revealed improved energy consumption and current efficiency in comparison to pure sulfonated polyethersulfone (SPES). ${ }^{125}$ Attachment of polymer chains to nanoparticles is an option which improves the interfacial compatibility between nanofiller and polymer substrate. 


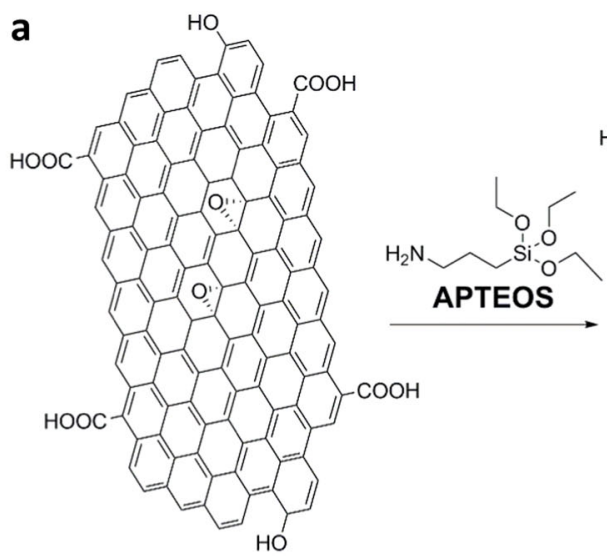

GO

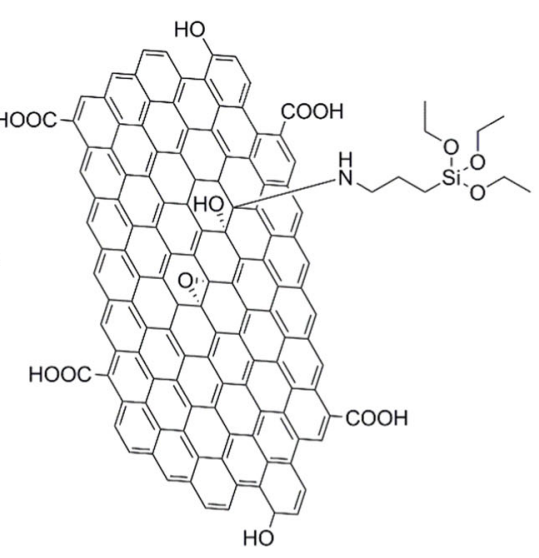

A-GO
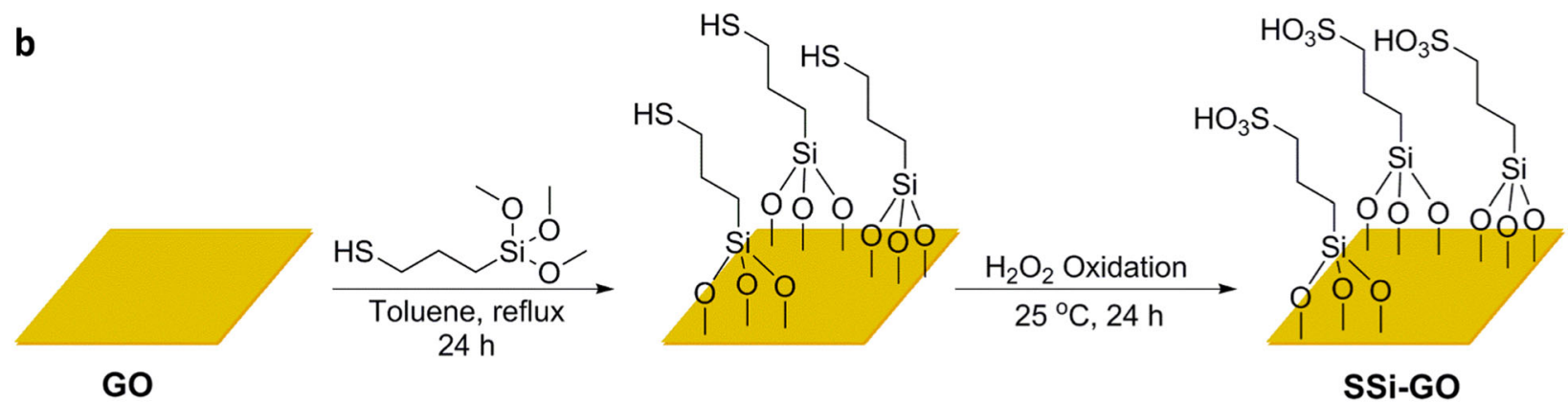

GO
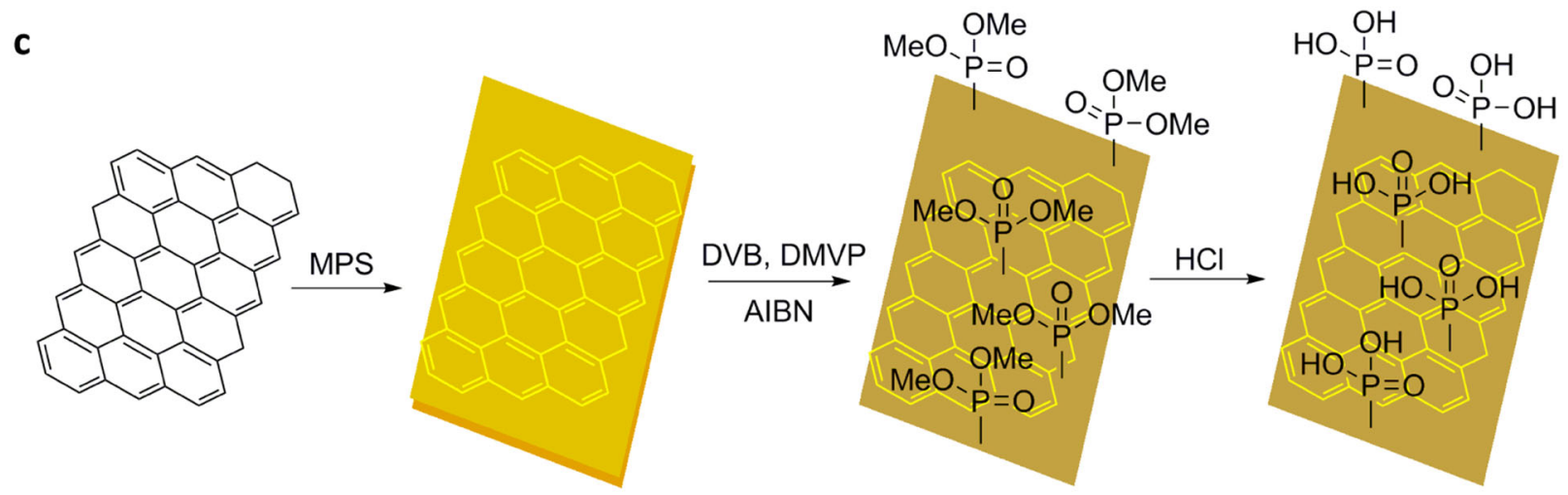

GO

PGO

Fig. 8 Some routes for functionalizing GO which have been utilized in IEMs. a Functionalization of GO by 3-aminopropyltriethoxysilane (APTEOS). ${ }^{36}$ b Synthesis of sulfonated organosilane functionalized GO (SSi-GO) from GO and (3-mercaptopropyl) trimethoxysilane (MPTMS). ${ }^{103}$ c Preparation of phosphonated GO (PGO) nanosheets via a series of reactions of GO with 3-(methacryloxy) propyltrimethoxysilane (MPS), dimethyl vinylphosphonate (DMVP), divinylbenzene (DVB), 2,2'-azobisisobutyronitrile (AIBN), and hydrochloric acid (HCI). ${ }^{34}$ Schemes adapted with permission from: a ref. ${ }^{36}$, ๔ 2015 Royal Society of Chemistry; b ref. ${ }^{103}$, ( 2013 Elsevier; c ref. ${ }^{34}$, ๔ 2015 Elsevier

Accordingly, the incorporation of polybenzimidazole functionalized silica $\left(\mathrm{PBI}^{-\mathrm{SiO}_{2}}\right)$ nanoparticles (see Fig. 9c for fabrication scheme) into polybenzimidazole (PBI) based CEMs resulted in superior thermal stability, mechanical strength, and ionic conductivity when compared to the virgin polybenzimidazole (PBI) membrane. ${ }^{126}$ Table 5 provides a detailed summary of some $\mathrm{SiO}_{2}-$ modified IEMs.

Other nanomaterials in ion exchange membrane nanocomposites This section deals with some NMs that have been used less frequently in conjunction with IEMs. The NMs discussed in this section include silver ( $\mathrm{Ag})$, Titanium (IV) oxide $\left(\mathrm{TiO}_{2}\right)$, Aluminum oxide $\left(\mathrm{Al}_{2} \mathrm{O}_{3}\right)$, Iron (II, III) oxide $\left(\mathrm{Fe}_{3} \mathrm{O}_{4}\right)$, zeolite, and Zinc oxide
( $\mathrm{ZnO})$. A detailed summary of the IEMs incorporated with these NMs is also given in Table 6.

Silver nanoparticles in ion exchange membranes. Silver nanoparticles are among the materials first utilized in the fabrication of polymer nanocomposites. ${ }^{127}$ The bactericidal ability of silver $\mathrm{NPs}^{128,129}$ has been greatly exploited in polymer nanocomposites for water treatment applications. ${ }^{130-134}$ In addition, the electrical conductivity of $\mathrm{Ag}$ has made these NPs draw a great deal of attention in the scientific domain. When used in IEMs, Ag NPs are usually coated on the surface of the membranes using any suitable coating technique, for example, magnetron sputtering. Although not as frequently used in IEMs compared to the hitherto discussed nanomaterials, the use of Ag NPs on IEMs has still 

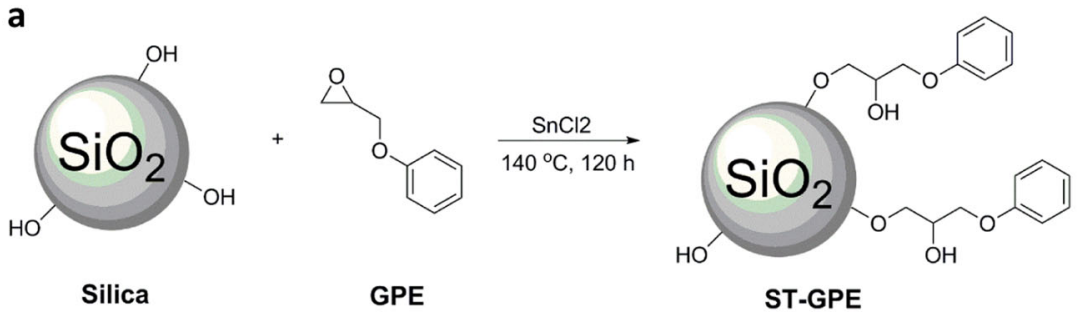<smiles></smiles>

Sulfonated $\mathrm{SiO}_{2}$ (SS)

b

C<smiles>O=C(O)c1ccc(N2C(=O)C=CC2=O)cc1</smiles>

pCPM
$\mathrm{MeO}$<smiles>CO[Si](CCc1ccc(S(=O)(=O)Cl)cc1)(OC)OC</smiles>

$\underset{13 \mathrm{~h}}{\stackrel{\text { Toluene }}{\longrightarrow}}$

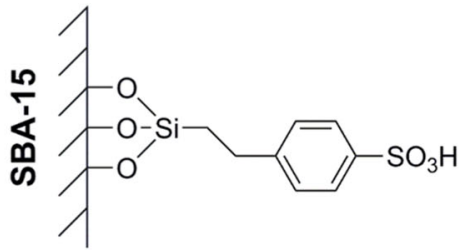<smiles>[R][CH]C(C)OC(=O)c1ccc(N2C(=O)C=CC2=O)cc1</smiles>

pCPM-SiO 2<smiles>Cc1cccc(-c2nc3ccc(-c4ccc5nc(C)[nH]c5c4)cc3[nH]2)c1</smiles>

PBI

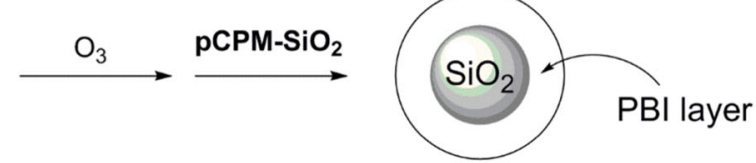

$\mathrm{PBI}_{-\mathrm{SiO}_{2}}$ nanoparticle

Fig. 9 Some routes for functionalizing silica nanoparticles. a Sulfonation of silica using glycidyl phenyl ether (GPE) and fuming sulfuric acid. ${ }^{159}$ b Phenylethylsulfonyl functionalization of mesoporous silica. Mesoporous silica was prepared by reacting Pluronic P123 triblock copolymer surfactant in aqueous $\mathrm{HCl}$ with TEOS, followed by calcination of the obtained powder to remove the triblock copolymer organic component. The obtained mesoporous silica was then functionalized using toluene and (Chlorosulfonylphenyl) ethyltrimethoxysilane in a dichloromethane solution. ${ }^{160}$ c Formation of polybenzimidazole functionalized silica $\left(\mathrm{PBI}_{-} \mathrm{SiO}_{2}\right)$ nanoparticles synthesized by chemically bonding polybenzimidazole (PBI) to $\mathrm{SiO}_{2}$ via an ozone-facilitated procedure using $\mathrm{N}$-(p-carboxyphenyl)maleimide (pCPM) functionalized $\mathrm{SiO}_{2}$ (pCPM-SiO ${ }_{2}$ ) as precursors. ${ }^{126}$ Schemes adapted with permission from: a ref. ${ }^{159}$, ( 2005 ACS; b ref. ${ }^{160}$, ( 2011 Elsevier; c ref. ${ }^{126}$, ( 2012 Elsevier

reaped some beneficial outcomes. ${ }^{135,136}$ For instance, substantial antibacterial properties were observed when Ag was applied as coating on acrylonitrile butadiene styrene (ABS)-based AEMs. ${ }^{135}$ Improvements in permselectivity, ionic permeability, ionic flux, ionic conductivity, thermal stability, and membrane potential were also noted for the Ag-coated AEMs in comparison to their unmodified counterparts.

Titanium dioxide $\left(\mathrm{TiO}_{2}\right)$ in ion exchange membranes. Titanium dioxide is a widely studied semiconductor due to its photocatalytic activity. Its low cost, good stability and high-efficiency play a significant role in the amount of attention it has received in the photocatalysis field. ${ }^{137} \mathrm{~A}$ number of research studies have also considered $\mathrm{TiO}_{2}$ as fillers in IEMs and report promising results. Demonstrations of improvements in IEC and ionic conductivity of
Nafion/ $/ \mathrm{TiO}_{2}$ nanocomposite CEMs compared to plain Nafion have been published. ${ }^{138}$ Enhancements in the mechanical strength of Nafion, when embedded with $\mathrm{TiO}_{2}$ nanowires, was reported. ${ }^{139}$ Studies conducted on the inclusion of $\mathrm{TiO}_{2}$ nanoparticles into quaternized polysulfone (QPSU) AEMs noted increments in the ionic conductivity. ${ }^{140}$ The inclusion of sulfonated $\mathrm{TiO}_{2}$ nanotubes ( $\mathrm{S}-\mathrm{TiO}_{2} \mathrm{NTs}$ ) in Nafion for fuel cell applications was investigated by Jun et al. ${ }^{141}$. The authors observed higher ionic conductivity values for the Nafion/S-TiO 2 NTs CEMs when compared to the plain Nafion membrane.

Aluminum oxide $\left(\mathrm{Al}_{2} \mathrm{O}_{3}\right)$ in ion exchange membranes. Research on the subject of the incorporation of $\mathrm{Al}_{2} \mathrm{O}_{3} \mathrm{NPs}$ in IEMs is even more scanty compared to the NMs in the previous sections. Notwithstanding, this class of inorganic NPs has some potential for use as 


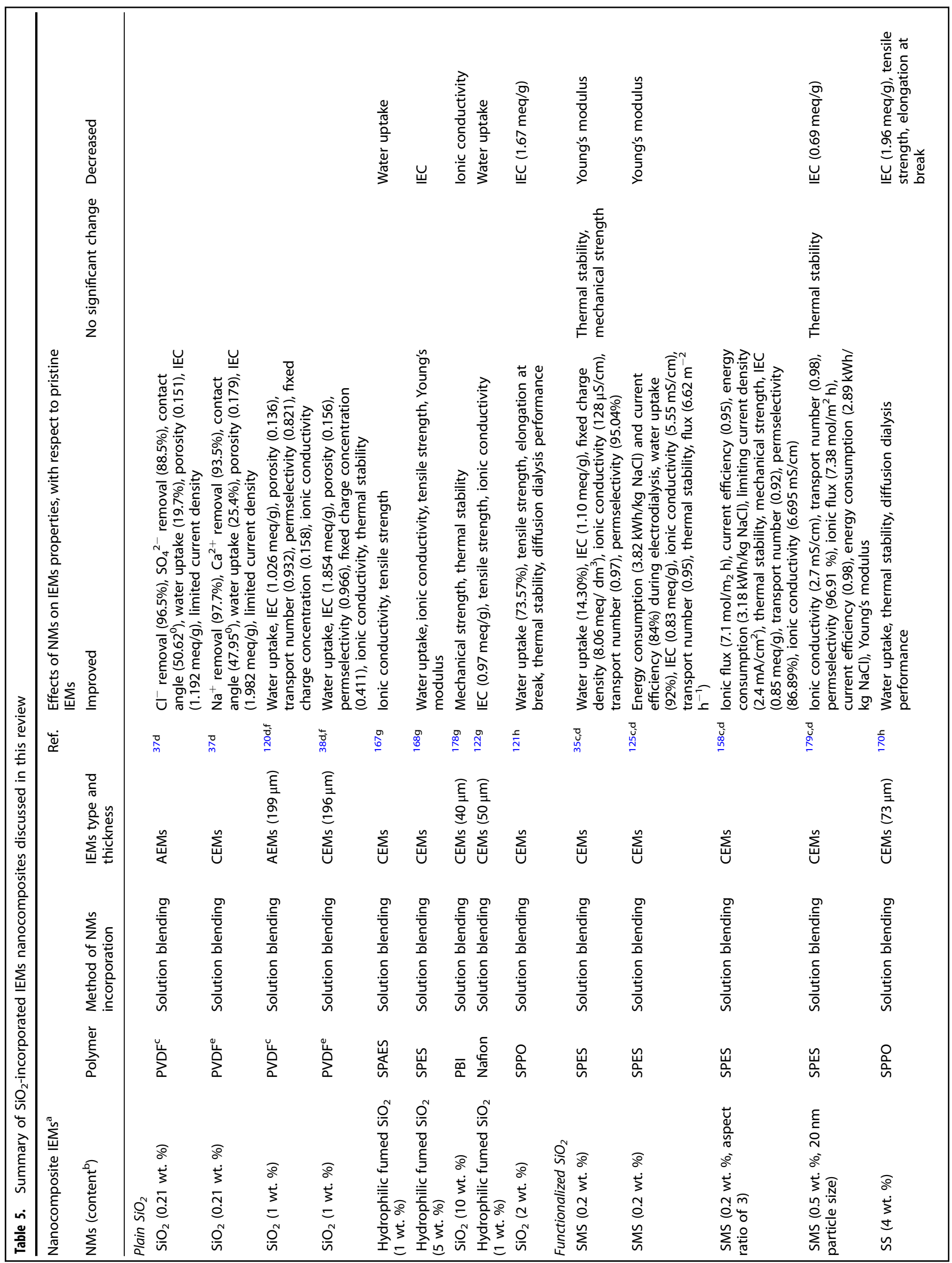


fillers in IEMs by virtue of its availability, stability, hydrophilicity and mechanical strength. ${ }^{127}$ In this regard, ED studies on $\mathrm{Al}_{2} \mathrm{O}_{3}$ NPs incorporated polyvinyl chloride (PVC) based CEMs exhibited increments in membrane potential, transport number, and permselectivity ionic flux, ionic permeability, and ionic conductivity. ${ }^{142}$ The IEC, was however observed to decrease at all NPs loadings perhaps due to isolation of the functional groups in the polymer matrix by the NPs. Funtionalization of the $\mathrm{Al}_{2} \mathrm{O}_{3} \mathrm{NPs}$ could be a way of offsetting this outcome.

Iron (II, III) oxide $\left(\mathrm{Fe}_{3} \mathrm{O}_{4}\right)$ nanoparticles in ion exchange membranes. The impressive magnetic and selective adsorption properties of $\mathrm{Fe}_{3} \mathrm{O}_{4} \mathrm{NPs}$ make them attractive candidates for water treatment applications. The use of $\mathrm{Fe}_{3} \mathrm{O}_{4} \mathrm{NPs}$ to enhance the physicochemical properties and separation efficacy of polymeric membranes has been investigated for a number of applications. ${ }^{143,144} \mathrm{Fe}_{3} \mathrm{O}_{4}$ NPs could also find applicability in enhancing the properties of IEMs. Considering this, polyvinyl chloride (PVC) based nanocomposite CEMs were prepared, by using with $\mathrm{Fe}_{3} \mathrm{O}_{4} \mathrm{NPs}$ as fillers with the aim of using for electrodialysis applications. ${ }^{145}$ The modified membranes possessed higher IEC, membrane potential, permselectivity, transport number, ionic flux, and ionic permeability in contrast to the pristine membrane.

Zeolite-assisted ion exchange membranes. Zeolite NPs possess high IEC and chemical stability, which make them suitable candidates for water treatment applications. ${ }^{146-149}$ Zeolite NPs were utilized in polyvinyl chloride (PVC) based nanocomposite CEMs fabricated for the purpose of ED research. ${ }^{150}$ The experimental results demonstrated improvements in membrane water content, membrane potential, transport number, permselectivity, ionic permeability, ionic flux, and ionic conductivity for the modified CEMs (at all NP loadings) in contrast to the virgin PVC CEMs. The improvements could be attributed to enhanced ionic transport properties that created more conducting regions in the membrane and promoted the ion transport between the solution and the membrane.

Zinc oxide $(\mathrm{ZnO})$ nanoparticles in ion exchange membranes. $\mathrm{ZnO}$ NPs are important nanomaterials that are well applied in photocatalysis, ${ }^{151}$ sensors, ${ }^{152,153}$ antibacterial materials, ${ }^{154,155}$ and dye sensitized solar cells. ${ }^{156}$ Additionally, the low cost and highsurface area of ZnO NPs make them attractive alternatives to other NMs. ${ }^{127}$ Assessments of polyvinyl chloride (PVC) based CEMs embedded with ZnO NPs showed higher permselectivity, transport number, membrane potential, ionic flux, and ionic permeability in contrast to the virgin CEMs. ${ }^{157}$

\section{OPTIMIZING THE PERFORMANCE OF NANOCOMPOSITE ION EXCHANGE MEMBRANES}

Numerous factors influence the properties and performance of nanocomposite IEMs. The quantity of NMs incorporated into the IEMs has received the most attention in nanocomposite IEMs research. Regarding this, we note that in some works the IEMs performance displays positive correlations with the NMs content, whereas others report inconsistent correlations of IEMs properties with the NMs content. Nevertheless, the majority note improvements in IEMs properties and performance at some particular NMs content. It has also been shown that NMs (in certain quantities, types, or forms) may produce less desired outcomes, for example: (1) very low-NMs content may be insufficient to improve IEMs performances, whereas excessive NMs content makes the nanocomposite IEMs brittle, resulting in a reduction of their mechanical strength (see Fig. 10); (2) the reduction of the IEC of IEMs due to enshrouding and isolation of the functional groups by excessive amounts of NMs, hence rendering the functional groups inaccessible for ion exchange. Ultimately, optimization of the NMs 


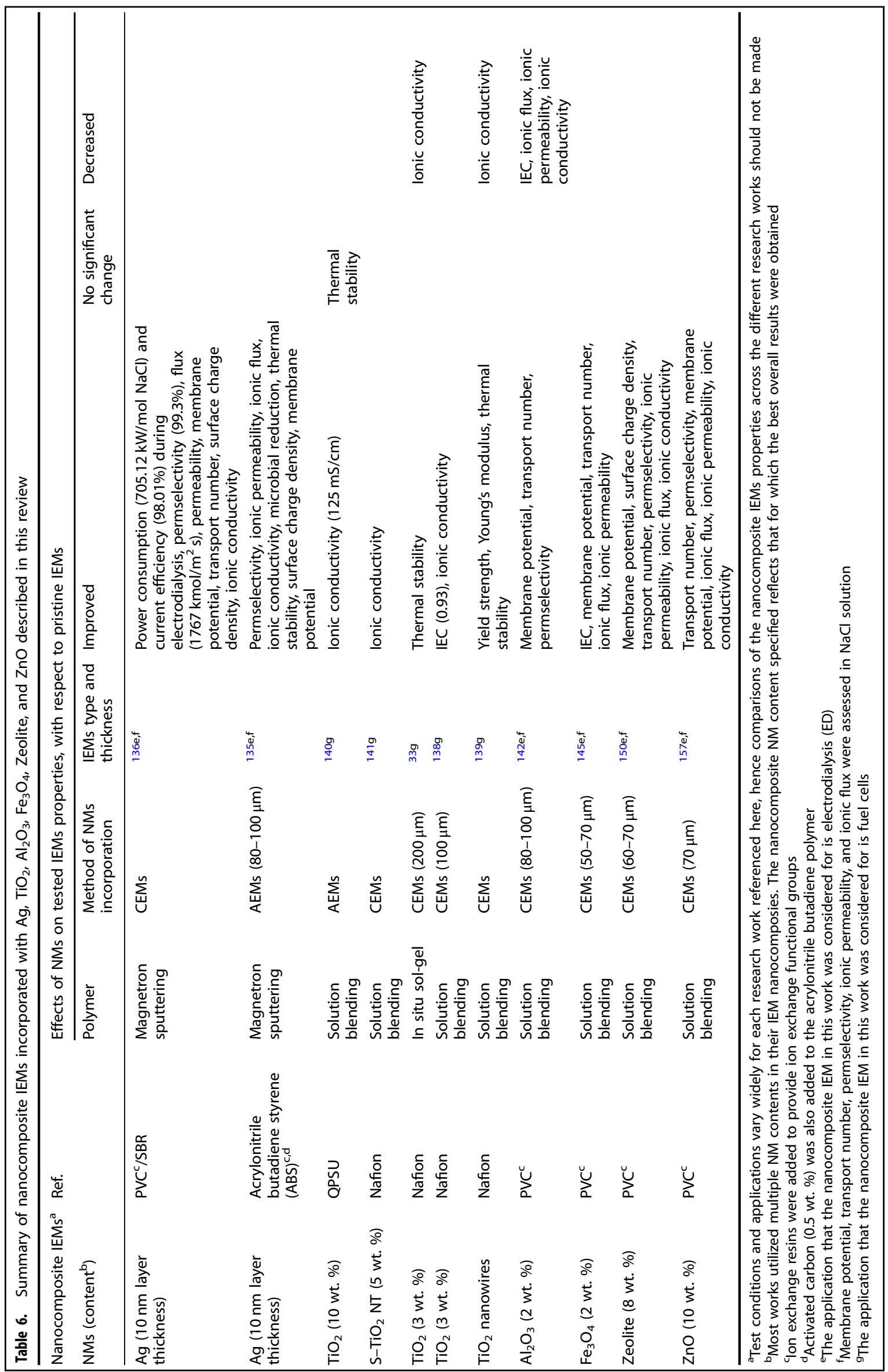



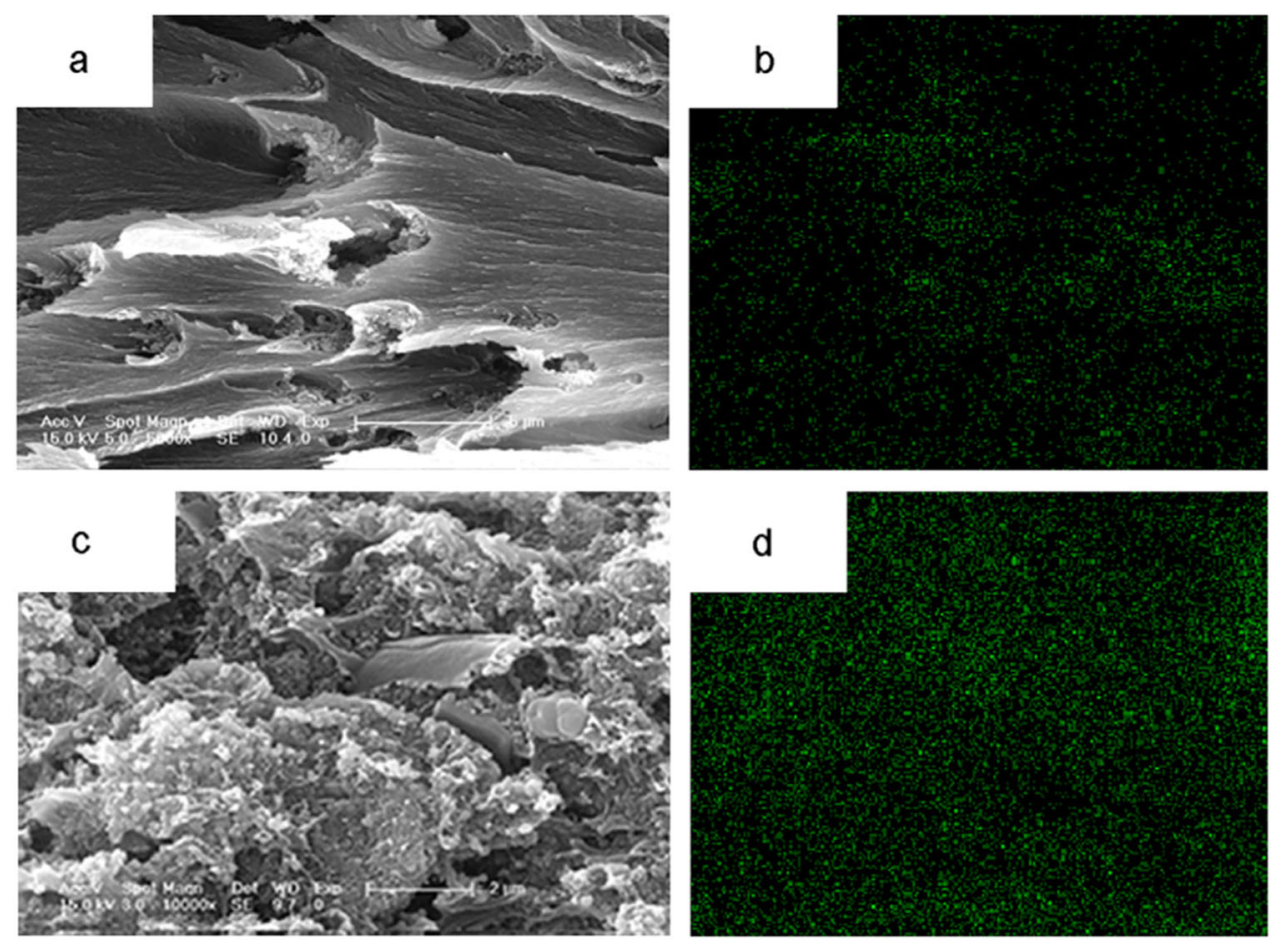

Fig. 10 Effect of NMs content on aggregation and consequently mechanical strength of IEMs. $\mathbf{a}, \mathbf{b}$ Cross-section and Si elemental analysis of sulfonated polyimide/sulfonated mesoporous silica (SPI/SMS) with 3 wt. \% SMS. c, d Cross-section and Si elemental analysis of SPI/SMS with 10 wt. \% SMS. This figure depicts the uniform dispersion (a) and aggregation (c) of SMS in SPI based IEMs. ${ }^{161}$ The elemental analysis gives a qualitative indication of the Si content in each of the IEMs. The increased aggregation led to a drastic decline in the mechanical strength (the tensile strength reduced from 48 to $24 \mathrm{MPa}$, the elastic modulus fell from 912 to $586 \mathrm{MPa}$, and the elongation at break dropped from 11.0 to 2.9\%). Figure reproduced with permission from ref. ${ }^{161}$, ๔ 2011 Elsevier

Table 7. Some properties of graphene-based $\mathrm{NMs}^{90}$

\begin{tabular}{|c|c|c|c|}
\hline Properties & Graphene & Graphene oxide (GO) & $\begin{array}{l}\text { Reduced graphene oxide } \\
\text { (rGO) }\end{array}$ \\
\hline Synthesis & $\begin{array}{l}\text { Chemical vapor deposition, thermal decomposition of silicon } \\
\text { carbide (SiC), graphite exfoliation }\end{array}$ & $\begin{array}{l}\text { Oxidation and exfoliation of } \\
\text { graphite }\end{array}$ & $\begin{array}{l}\text { Reduction of graphene } \\
\text { oxide }\end{array}$ \\
\hline C:O ratio & No oxygen & $2-4$ & $8-246$ \\
\hline Young's modulus (TPa) & 1 & 0.2 & 0.25 \\
\hline $\begin{array}{l}\text { Electron mobility }\left(\mathrm{cm}^{2}\right. \\
\left.\mathrm{V}^{-1} \mathrm{~s}^{-1}\right)\end{array}$ & $10,000-50,000$ & Insulator & $0.05-200$ \\
\hline
\end{tabular}

composition and properties is necessary to obtain nanocomposite IEMs with the most desirable overall IEMs performance.

Figure 11, which was created to analyze the IEC of the different nanocomposite IEMs, enables a comparison between the effects of the different NMs on the IEMs, and also the provision of directions for further research. The analysis was performed for IEMs nanocomposites for which IEC data were available. These included IEMs incorporated with CNTs, graphene-based NMs and silica NPs. The insights from the analysis include: (1) lower content of MWCNTs and functionalization of MWCNTs produced increments in the IEC of IEMs; (2) functionalized GO had greater impact on improving the IEC of IEMs compared to plain GO. The effective weight content for the GO-based NMs appears to be from 0.5 to 5 wt. \%; (3) both plain and functionalized silica have positive effects on IEC from content range of $0.2-1 \mathrm{wt}$. \%. The silica content seems to be of more importance than its functionalization with regards to improving the IEC of IEMs.
It has also been discovered that other considerations, such as particle size, aspect ratio, etc., play a significant role in the overall IEMs performance. For instance: (1) better distribution of ionic clusters and optimum IEMs performance was observed with incorporation of graphene oxide (GO) particles with smaller particle size (see Fig. 12) ${ }_{i}^{43}$ (2) Sulfonated mesoporous silicon (IV) oxide (SMS) with bigger aspect ratios inclined to form larger clusters and bigger pores as a result of their poor dispersion in sulfonated polyethersulfone (SPES)-based CEMs. ${ }^{158}$

In order to identify the most suitable NMs for IEMs, more comparative information of the NMs and their effects in IEMs are needed, which can be provided by conducting well designed comparative studies under standardized conditions. We believe that the parametric experiments with some selected NMs and IEMs combinations can certainly provide a glimpse of insights of such attempts. However, given the large number of possible combinations of the variables, computational modeling and 

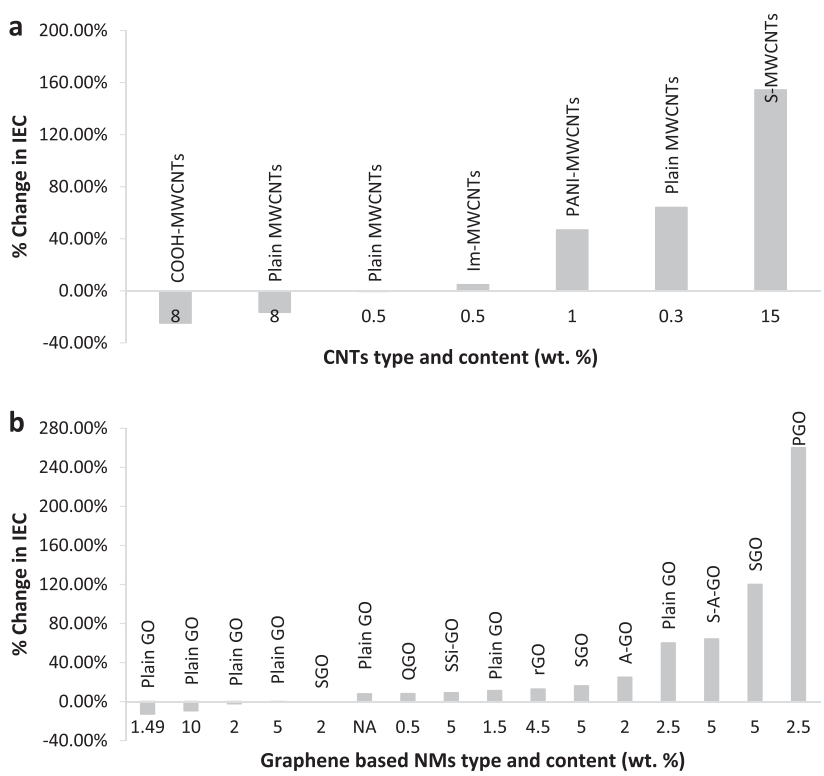

C $120.00 \%$

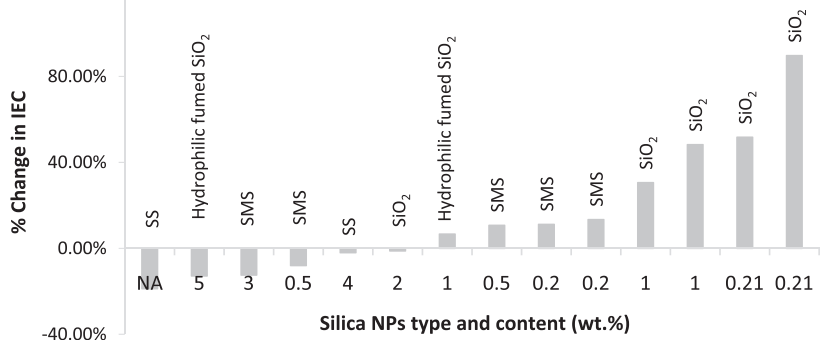

Fig. 11 Evaluation of the effects of NMs on the IEC of IEMs. a Change in IEC of IEMs with incorporation of CNTs. In most of the cases, lower content of CNTs resulted in increments in IEC. Also, more instances of improved IEC are observed for the cases where the MWCNTs are functionalized. $\mathbf{b}$ Effects of graphene-based NMs on the IEC of IEMs. All the lower IEC values are obtained for plain GO. Majority of the improved cases involve the incorporation of functionalized GO. From the analysis of the chart, the effective content of GO-based NMs is from 0.5 to 5 wt. \%. c Change in IEC of IEMs upon incorporation of silica-based NPs. Some good results are obtained when silica is functionalized, but it appears the content of the silica impacts the results significantly. For silica contents from 0.2 to $1 \mathrm{wt}$. \%, increments in IEC is noticed for plain and functionalized silica NPs. Whereas, a decrease in IEC is observed for silica NPs content above $1 \mathrm{wt}$.\%. From this chart, the effective silica NPs content is from 0.2 to $1 \mathrm{wt}$. \%

simulation would also need to be used in tandem with laboratory experimental research to arrive at important findings within a reasonable time frame. It is also expected that factors, such as availability, cost, and ease of preparation, could have a deciding influence on the choices of employing NMs to develop nanocomposite IEMs for electromembrane desalination.

\section{CONCLUSION, EMERGING TRENDS, AND FUTURE DIRECTIONS}

This article, in which some of the developments in nanocomposite IEMs are reviewed, strongly indicates that NMs-incorporated IEMs can be considered as beneficial candidates for enhancing electromembrane desalination. Key recent achievements in nanocomposite IEMs research have focused on utilizing carbon nanotubes, graphene-based NMs, silica, titanium dioxide, silver, etc. in improving the properties of IEMs as regards IEC, permselectivity, ionic conductivity, mechanical strength, and thermal stability-although at the laboratory scale. In addition, the few desalination tests performed have demonstrated improved performances in comparison to the unmodified IEMs. While nanotechnology suggests a promising route for enhancing IEMs' capabilities for application in desalination, the use of nanocomposite IEMs for electromembrane desalination is still in its early stage and the many remaining issues have to be further investigated in order to make a meaningful transition from potential applications to successful commercial implementations.

We identified that, out of the 65 nanocomposite IEMs described in Tables 3-6, 53 of them were CEMs and 12 of them were AEMs (see Fig. 13). In terms of application, 42 were assessed for fuel cells, 23 were analyzed for electromembrane desalination (22 ascribed to ED and 1 to membrane capacitive deionization), and 2 were tested for diffusion dialysis. Since IEMs are an integral part of the electromembrane desalination unit, the assessment of nanocomposite IEMs under operational electromembrane desalination conditions is essential. In addition, investigations of nanocomposite AEMs should also be encouraged in order to ensure the simultaneous availability of both superior AEMs and CEMs for advancements in electromembrane desalination technologies.

Given the varieties of polymers, NMs, and preparation routes for IEMs nanocomposites, the prospects for research in the nanocomposite IEMs field is quite open. There are therefore many opportunities for investigation of NMs-assisted IEMs. With respect to the NMs/polymer blending ratio, the optimum NMs content to be employed in nanocomposite IEMs greatly differs depending on the polymer type, the functional groups available in the polymer or NMs, etc. Numerous routes to achieve functionalization of the NMs are also reported in literature. It is therefore imperative to have a good understanding of the characteristics of the candidate NMs. Experimental decisions should be made based on utilizing the advantageous properties that can be offered by the NMs, as well as looking for the synergistic effects arising from the interactions between the incorporated NMs with the polymeric matrix. The ultimate outcome of incorporating NMs in IEMs is to achieve not only isolated benefits, but also to derive synergistic positive effects on the overall performance and other aspects such as cost. In addition, numeric modeling and simulation would also be used in tandem with laboratory experimental research to arrive at significant findings. We however note that the ease of mass production of the NMs will influence the consideration of any of the NMs. Among the NMs discussed in this review MWCNTs, graphene-based NMs, and silica NPs have been identified as the more promising NMs because they have received the most interest and also produced more of the beneficial results. Based on the analysis of the available IEC data, the following observations were made: (1) lower content of MWCNTs and functionalization of MWCNTs yielded more improvements; (2) functionalized GO was beneficial in comparison to plain GO; (3) silica NPs were most effective from content range of 0.2-1 wt. \%.

Two mechanisms by which NMs improve the electrochemical properties of IEMs have been proposed: (1) the incremental increase in ionic group concentration; and (2) the ionic cluster dispersion mechanism (ICDM) which promotes the creation of ion conducting routes. Between these two mechanisms, the latter appears to offer the more convincing explanation for the improvements. Nevertheless, the precise mechanism by which any of the NMs augments the IEMs performance remains largely unknown. As such, procedures for forecasting the effects that a NM would have on an IEM a priori are yet to be well established. Furthermore, any direct comparison between the nanocomposite IEMs synthesized in the different research works needs to be done with care because the test conditions varied greatly for each of the studies. Hence, there is the need for more standardized experimental conditions such as test solutions, testing equipment and methods, so that the performance of the different NMs in nanocomposite IEMs can be accurately assessed and the hypotheses of the mechanisms can be verified. 

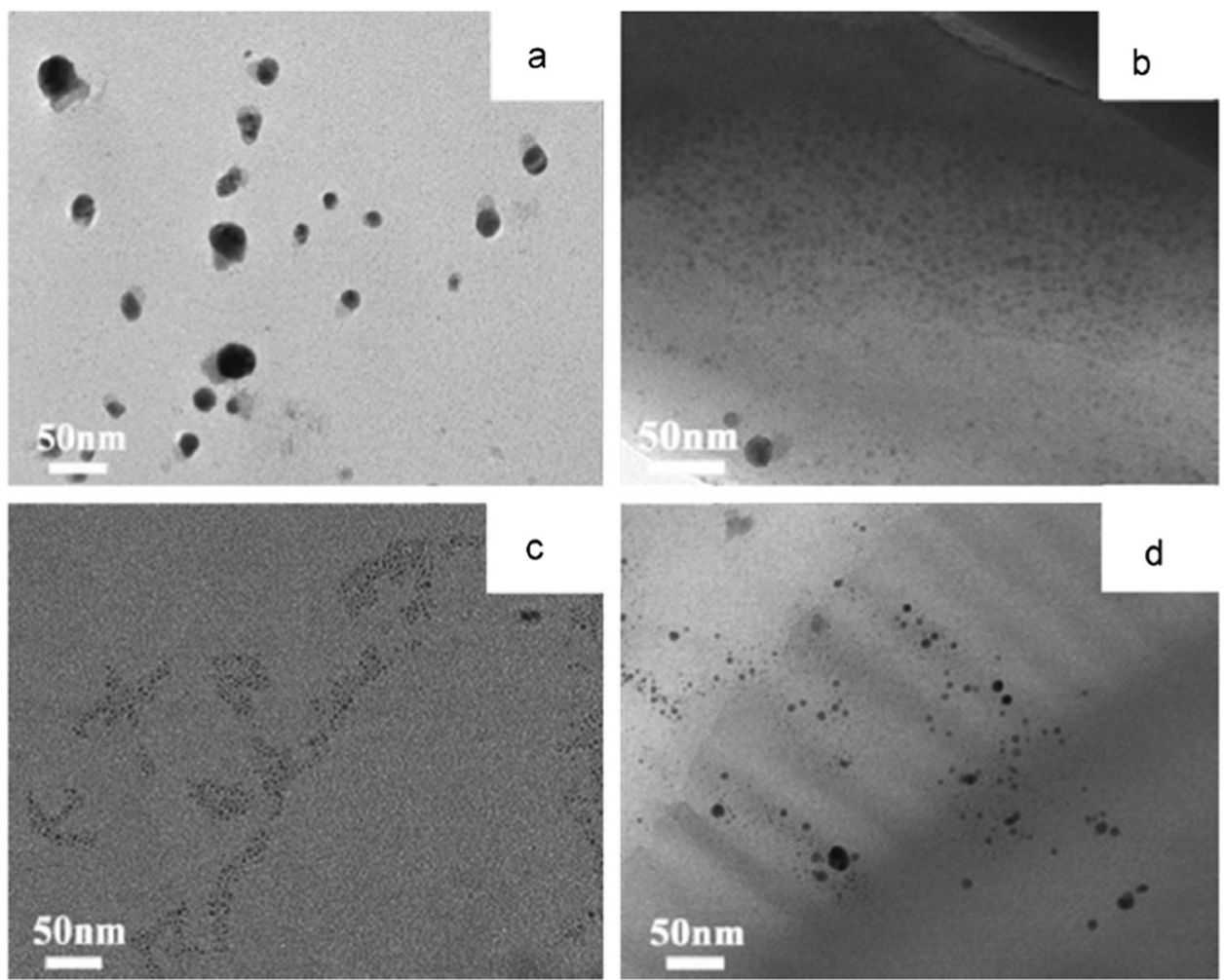

Fig. 12 TEM micrographs of sulfonated polyimide (SPI) based CEMs showing effect of size of GO on distribution of ionic cluster. a pure SPI. bd SPI with GO. Size of GO incorporated into the SPI increased from b-d. ${ }^{43}$ The dark-silver stained spherical regions revealed better distribution of the ionic clusters for IEMs embedded with the GO having the smallest particle size i.e. $\mathbf{b}$. This was due to the higher degree of oxidation and high-carboxyl content of this GO, which caused stronger electrostatic attractions between the GO and SPI polymer matrix. The stronger interactions encouraged shrinkage of the sulfonic groups of the SPI and consequently prevented aggregation into bigger ionic clusters

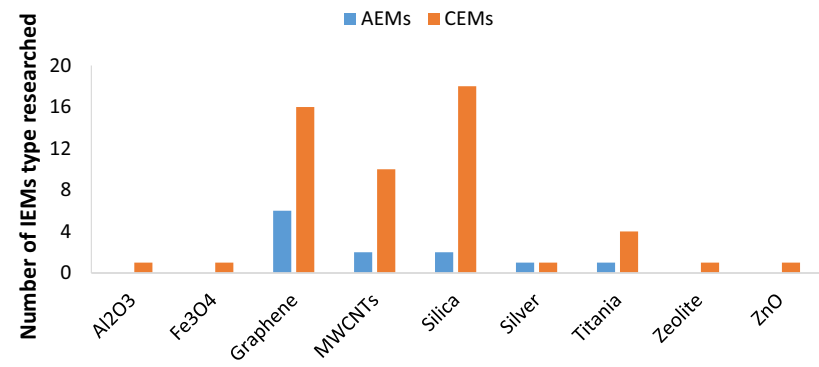

NMs type

Fig. 13 Categories of IEMs nanocomposites reported in this work

As the IEMs nanocomposite studies are still in the research stage, no pilot scale assessments have been conducted yet. For a fast assimilation of this technology, the research in this technology will have to go beyond the lab scale. So far, there has been little focus on membrane fouling studies in IEMs nanocomposites. This is also an aspect that cannot be neglected if the research of IEMs nanocomposites is to result in breakthroughs in water desalination and purification technologies. Furthermore, there is the need to assess the separation efficacy of the nanocomposite IEMs with regards to different kind of ions (e.g., monovalent ions, divalent ions, etc.). The life span of the membranes also needs to be ascertained. Efforts must also be made to investigate more ecofriendly routes for synthesizing IEMs nanocomposites. As of now, most of the solvents used in the laboratory are harmful or toxic. This toxicity can be addressed by making use of green solvents. Research into more environmentally friendly solvents for synthesizing IEMs nanocomposites should be encouraged. In addition, the environmental impact of utilizing NMs requires thorough studies before NMs can be widely adopted for any mainstream application.

By highlighting some of the challenges and opportunities in nanocomposite IEMs for electromembrane desalination, the intention of this article is to foster interest in this research topic and get closer to effectively addressing global water security challenges.

\section{ACKNOWLEDGEMENTS}

This material is part of the collaborative project between Masdar Institute-Khalifa University of Science and Technology and University of Manchester (SMG2016000001). The authors acknowledge the financial support of Khalifa University of Science and Technology, United Arab Emirates.

\section{AUTHOR CONTRIBUTIONS}

A.A. and L.Z. designed the structure of the manuscript, drafted the first version of the manuscript and incorporated major revisions to subsequent versions. A.A.H., L.C., and G.S. have made numerous suggestions and revisions to enhance the clarity of the overall contents. P.B. has made very valuable inputs on the logic behind the review and on improving the readability of the work.

\section{ADDITIONAL INFORMATION}

Competing Interests: The authors declare that they have no conflict of interest.

Publisher's note: Springer Nature remains neutral with regard to jurisdictional claims in published maps and institutional affiliations. 


\section{REFERENCES}

1. Strathmann, H., Grabowski, A. \& Eigenberger, G. Electromembrane processes, efficient and versatile tools in a sustainable industrial development. Desalination 199, 1-3 (2006)

2. Baker, R. W. Membrane Technology and Applications. 3rd edn, 1-575, (Wiley, 2012).

3. Mulder, M. Basic Principles of Membrane Technology. 2nd edn, 1-556, (Kluwer Academic Publishers, 2003).

4. Strathmann, H. lon-Exchange Membrane Separation Processes. 1st edn, (Elsevier 2004)

5. Sata, T. Ion Exchange Membranes: Preparation, Characterization, Modification and Application. (The Royal Society of chemistry, 2004).

6. Nagarale, R. K., Gohil, G. S., Shahi, V. K. \& Rangarajan, R. Preparation and electrochemical characterizations of cation-exchange membranes with different functional groups. Colloids Surf. A 251, 133-140 (2004).

7. Kosmala, B. \& Schauer, J. lon-exchange membranes prepared by blending sulfonated poly (2, 6-dimethyl-1, 4-phenylene oxide) with polybenzimidazole. J. Appl. Polym. Sci. 85, 1118-1127 (2002).

8. Cui, W., Kerres, J. \& Eigenberger, G. Development and characterization of ionexchange polymer blend membranes. Sep. Purif. Technol. 14, 145-154 (1998).

9. Robertson, N. J. et al. Tunable high performance cross-linked alkaline anion exchange membranes for fuel cell applications. J. Am. Chem. Soc. 132, 3400-3404 (2010).

10. Vyas, P. V., Ray, P., Adhikary, S. K., Shah, B. G. \& Rangarajan, R. Studies of the effect of variation of blend ratio on permselectivity and heterogeneity of ionexchange membranes. J. Colloid Interface Sci. 257, 127-134 (2003).

11. Won, J. et al. Structural characterization and surface modification of sulfonated polystyrene-(ethylene-butylene)-styrene triblock proton exchange membranes. J. Membr. Sci. 214, 245-257 (2003).

12. Kim, D. J., Jo, M. J. \& Nam, S. Y. A review of polymer-nanocomposite electrolyte membranes for fuel cell application. J. Ind. Eng. Chem. 21, 36-52 (2015).

13. Mishra, A. K., Bose, S., Kuila, T., Kim, N. H. \& Lee, J. H. Silicate-based polymernanocomposite membranes for polymer electrolyte membrane fuel cells. Prog. Polym. Sci. 37, 842-869 (2012).

14. Hosseini, S. M., Madaeni, S. S., Heidari, A. R. \& Amirimehr, A. Preparation and characterization of ion-selective polyvinyl chloride based heterogeneous cation exchange membrane modified by magnetic iron-nickel oxide nanoparticles. Desalination 284, 191-199 (2012).

15. Zendehnam, A., Arabzadegan, M., Hosseini, S. M., Robatmili, N. \& Madaeni, S. S. Fabrication and modification of polyvinyl chloride based heterogeneous cation exchange membranes by simultaneously using Fe-Ni oxide nanoparticles and Ag nanolayer: physico-chemical and antibacterial characteristics. Korean J. Chem. Eng. 30, 1265-1271 (2013).

16. Sigma-Aldrich. Iron nickel oxide, http://www.sigmaaldrich.com/catalog/product/ aldrich/637149?lang=en\&region $=A E$ (2017).

17. American-Elements. Iron Nickel Oxide Nanoparticles/Nanopowder, https://www. americanelements.com/iron-nickel-oxide-nanoparticles-nanopowder-12168-546 (2017).

18. $\mathrm{Xu}, \mathrm{T}$. Ion exchange membranes: state of their development and perspective. $J$ Membr. Sci. 263, 1-29 (2005).

19. Merle, G., Wessling, M. \& Nijmeijer, K. Anion exchange membranes for alkaline fuel cells: a review. J. Membr. Sci. 377, 1-35 (2011).

20. Nagarale, R. K., Gohil, G. S. \& Shahi, V. K. Recent developments on ion-exchange membranes and electro-membrane processes. Adv. Colloid Interface Sci. 119, 97-130 (2006).

21. Yee, R. S. L., Rozendal, R. A., Zhang, K. \& Ladewig, B. P. Cost effective cation exchange membranes: a review. Chem. Eng. Res. Des. 90, 950-959 (2012).

22. Tripathi, B. P. \& Shahi, V. K. Organic-inorganic nanocomposite polymer electrolyte membranes for fuel cell applications. Prog. Polym. Sci. 36, 945-979 (2011).

23. Vogel, C. \& Meier-Haack, J. Preparation of ion-exchange materials and membranes. Desalination 342, 156-174 (2014).

24. Strathmann, H., Grabowski, A. \& Eigenberger, G. lon-exchange membranes in the chemical process industry. Ind. Eng. Chem. Res. 52, 10364-10379 (2013).

25. Bernardes, A., Rodrigues, M. A. S. \& Ferreira, J. Z. Electrodialysis and Water Reuse. First edn, (Springer-Verlag Berlin Heidelberg, 2014).

26. Strathmann, H. Introduction to membrane science and technology. (Wiley-VCH Weinheim, 2013).

27. Strathmann, H. Electrodialysis, a mature technology with a multitude of new applications. Desalination 264, 268-288 (2010).

28. Salam, H., Dong, Y. \& Davies, I. in Fillers and Reinforcements for Advanced Nanocomposites Woodhead Publishing Series in Composites Science and Engineering (eds Yu Dong, Rehan Umer, \& Alan Kin Tak Lau) 101-132 (Woodhead Publishing, 2015).

29. Banerjee, S., Lee, J. H., Kuila, T. \& Kim, N. H. in Fillers and Reinforcements for Advanced Nanocomposites Woodhead Publishing Series in Composites Science and
Engineering (eds Yu Dong, Rehan Umer, \& Alan Kin Tak Lau) 133-156 (Woodhead Publishing, 2015).

30. Vatanpour, V., Madaeni, S. S., Moradian, R., Zinadini, S. \& Astinchap, B. Nove antibifouling nanofiltration polyethersulfone membrane fabricated from embedding $\mathrm{TiO}_{2}$ coated multiwalled carbon nanotubes. Sep. Purif. Technol. 90, 69-82 (2012).

31. Moghadassi, A. R., Koranian, P., Hosseini, S. M., Askari, M. \& Madaeni, S. S. Surface modification of heterogeneous cation exchange membrane through simultaneous using polymerization of PAA and multi walled carbon nano tubes. J. Ind. Eng. Chem. 20, 2710-2718 (2014).

32. Thomassin, J.-M. et al. Beneficial effect of carbon nanotubes on the performances of Nafion membranes in fuel cell applications. J. Membr. Sci. 303, 252-257 (2007).

33. Amjadi, M., Rowshanzamir, S., Peighambardoust, S. J., Hosseini, M. G. \& Eikani, M $\mathrm{H}$. Investigation of physical properties and cell performance of $\mathrm{Nafion} / \mathrm{TiO}_{2}$ nanocomposite membranes for high temperature PEM fuel cells. Int. J. Hydrog. Energy 35, 9252-9260 (2010).

34. Bai, $\mathrm{H}$. et al. Anhydrous proton exchange membranes comprising of chitosan and phosphorylated graphene oxide for elevated temperature fuel cells. J. Membr. Sci. 495, 48-60 (2015).

35. Klaysom, C., Marschall, R., Wang, L., Ladewig, B. P. \& Lu, G. Q. M. Synthesis of composite ion-exchange membranes and their electrochemical properties for desalination applications. J. Mater. Chem. 20, 4669-4674 (2010).

36. Sharma, P. P., Gahlot, S., Bhil, B. M., Gupta, H. \& Kulshrestha, V. An environmentally friendly process for the synthesis of an $\mathrm{fGO}$ modified anion exchange membrane for electro-membrane applications. RSC Adv. 5, 38712-38721 (2015)

37. Zuo, X., Yu, S. \& Shi, W. Effect of some parameters on the performance of eletrodialysis using new type of PVDF- $\mathrm{SiO}_{2}$ ion-exchange membranes with single salt solution. Desalination 290, 83-88 (2012).

38. Zuo, X. et al. Preparation of organic-inorganic hybrid cation-exchange membranes via blending method and their electrochemical characterization. J. Membr. Sci. 328, 23-30 (2009).

39. Liu, L., Tong, C., He, Y., Zhao, Y. \& Lü, C. Enhanced properties of quaternized graphenes reinforced polysulfone based composite anion exchange membranes for alkaline fuel cell. J. Membr. Sci. 487, 99-108 (2015).

40. Lee, D. C., Yang, H. N., Park, S. H. \& Kim, W. J. Nafion/graphene oxide composite membranes for low humidifying polymer electrolyte membrane fuel cell. $J$. Membr. Sci. 452, 20-28 (2014).

41. Tseng, C.-Y. et al. Sulfonated polyimide proton exchange membranes with graphene oxide show improved proton conductivity, methanol crossover impedance, and mechanical properties. Adv. Energy Mater. 1, 1220-1224 (2011).

42. Choi, B. G. et al. Innovative polymer nanocomposite electrolytes: nanoscale manipulation of ion channels by functionalized graphenes. ACS nano $\mathbf{5}$, 5167-5174 (2011).

43. He, Y., Tong, C., Geng, L., Liu, L. \& Lü, C. Enhanced performance of the sulfonated polyimide proton exchange membranes by graphene oxide: Size effect of graphene oxide. J. Membr. Sci. 458, 36-46 (2014).

44. Li, N., Zhang, F., Wang, J., Li, S. \& Zhang, S. Dispersions of carbon nanotubes in sulfonated poly[bis(benzimidazobenzisoquinolinones)] and their protonconducting composite membranes. Polymer 50, 3600-3608 (2009).

45. Hamada, N., Sawada, S.-i \& Oshiyama, A. New one-dimensional conductors: graphitic microtubules. Phys. Rev. Lett. 68, 1579-1581 (1992).

46. Iijima, S. \& Ichihashi, T. Single-shell carbon nanotubes of 1-nm diameter. Nature 363, 603-605 (1993).

47. Ebbesen, T. W. \& Ajayan, P. M. Large-scale synthesis of carbon nanotubes. Nature 358, 220-222 (1992)

48. Bethune, D. S. et al. Cobalt-catalysed growth of carbon nanotubes with singleatomic-layer walls. Nature 363, 605-607 (1993)

49. lijima, S. Carbon nanotubes: past, present, and future. Phys. B 323, 1-5 (2002).

50. lijima, S. Helical microtubules of graphitic carbon. Nature 354, 56-58 (1991).

51. Wei, B. Q., Vajtai, R. \& Ajayan, P. M. Reliability and current carrying capacity of carbon nanotubes. Appl. Phys. Lett. 79, 1172 (2001).

52. Tans, S. J., Verschueren, A. R. M. \& Dekker, C. Room-temperature transistor based on a single carbon nanotube. Nature 393, 49-52 (1998).

53. Charlier, J.-C., Blase, X. \& Roche, S. Electronic and transport properties of nanotubes. Rev. Mod. Phys. 79, 677-732 (2007).

54. Treacy, M. M. J., Ebbesen, T. W. \& Gibson, J. M. Exceptionally high Young's modulus observed for individual carbon nanotubes. Nature 381, 678-680 (1996).

55. Wong, E. W., Sheehan, P. E. \& Lieber, C. M. Nanobeam mechanics: elasticity, strength, and toughness of nanorods and nanotubes. Science 277, 1971-1975 (1997).

56. $\mathrm{Yu}, \mathrm{M} . \mathrm{F}$. et al. Strength and breaking mechanism of multiwalled carbon nanotubes under tensile load. Science 287, 637-640 (2000). 
57. Falvo, M. R. et al. Bending and buckling of carbon nanotubes under large strain. Nature 389, 582-584 (1997).

58. Poncharal, P., Wang, Z. L., Ugarte, D. \& De Heer, W. A. Electrostatic deflections and electromechanical resonances of carbon nanotubes. Science 283, 1513-1516 (1999).

59. Salvetat, J.-P. et al. Elastic modulus of ordered and disordered multiwalled carbon nanotubes. Adv. Mater. 11, 161-165 (1999).

60. Baughman, R. H., Zakhidov, A. A. \& de Heer, W. A. Carbon nanotubes--the route toward applications. Science 297, 787-792 (2002).

61. Ajayan, P. M. \& Zhou, O. Z. in Carbon Nanotubes: Synthesis, Structure, Properties, and Applications https://doi.org/10.1007/3-540-39947-x_14 (eds Mildred S. Dresselhaus, Gene Dresselhaus, \& Phaedon Avouris) 391-425 (Springer Berlin Heidelberg, 2001).

62. Endo, M., Strano, M. S. \& Ajayan, P. M. in Carbon Nanotubes: Advanced Topics in the Synthesis, Structure, Properties and Applications https://doi.org/10.1007/9783-540-72865-8_2 (eds Ado Jorio, Gene Dresselhaus, \& Mildred S. Dresselhaus) 13-62 (Springer Berlin Heidelberg, 2008).

63. Spitalsky, Z., Tasis, D., Papagelis, K. \& Galiotis, C. Carbon nanotube-polymer composites: chemistry, processing, mechanical and electrical properties. Prog. Polym. Sci. 35, 357-401 (2010).

64. Coleman, J. N., Khan, U., Blau, W. J. \& Gun'ko, Y. K. Small but strong: a review of the mechanical properties of carbon nanotube-polymer composites. Carbon $N$. Y. 44, 1624-1652 (2006).

65. Yun, S., Im, H., Heo, Y. \& Kim, J. Crosslinked sulfonated poly(vinyl alcohol)/ sulfonated multi-walled carbon nanotubes nanocomposite membranes for direct methanol fuel cells. J. Membr. Sci. 380, 208-215 (2011)

66. Hosseini, S. M., Madaeni, S. S. \& Khodabakhshi, A. R. Preparation and characterization of PC/SBR heterogeneous cation exchange membrane filled with carbon nano-tubes. J. Membr. Sci. 362, 550-559 (2010).

67. Ma, C. et al. Alignment and dispersion of functionalized carbon nanotubes in polymer composites induced by an electric field. Carbon N. Y. 46, 706-710 (2008).

68. Sharma, A., Kumar, S., Tripathi, B., Singh, M. \& Vijay, Y. K. Aligned CNT/Polymer nanocomposite membranes for hydrogen separation. Int. J. Hydrog. Energy 34, 3977-3982 (2009).

69. Lin, Y. et al. Polymeric carbon nanocomposites from carbon nanotubes functionalized with matrix polymer. Macromolecules 36, 7199-7204 (2003).

70. Chang, C.-M. \& Liu, Y.-L. Functionalization of multi-walled carbon nanotubes with non-reactive polymers through an ozone-mediated process for the preparation of a wide range of high performance polymer/carbon nanotube composites. Carbon N. Y. 48, 1289-1297 (2010).

71. Asgari, M. S., Nikazar, M., Molla-abbasi, P. \& Hasani-Sadrabadi, M. M. Nafion ${ }^{\otimes}$ histidine functionalized carbon nanotube: High-performance fuel cell membranes. Int. J. Hydrog. Energy 38, 5894-5902 (2013).

72. Hosseini, S. M. et al. Fabrication of mixed matrix heterogeneous ion exchange membrane by multiwalled carbon nanotubes: electrochemical characterization and transport properties of mono and bivalent cations. Desalination 329, 62-67 (2013).

73. Zendehnam, A., Mokhtari, S., Hosseini, S. M. \& Rabieyan, M. Fabrication of novel heterogeneous cation exchange membrane by use of synthesized carbon nanotubes-co-copper nanolayer composite nanoparticles: Characterization, performance in desalination. Desalination 347, 86-93 (2014).

74. Robin, J. J. in New Synthetic Methods https://doi.org/10.1007/b12304 35-80 (Springer Berlin Heidelberg, 2004).

75. Pan, W.-H., Lue, S. J., Chang, C.-M. \& Liu, Y.-L. Alkali doped polyvinyl alcohol/ multi-walled carbon nano-tube electrolyte for direct methanol alkaline fuel cell. J. Membr. Sci. 376, 225-232 (2011).

76. Geim, A. K. \& Novoselov, K. S. The rise of graphene. Nat. Mater. 6, 183-191 (2007).

77. Novoselov, K. S. et al. A roadmap for graphene. Nature 490, 192-200 (2012).

78. Frank, I. W., Tanenbaum, D. M., Van der Zande, A. M. \& McEuen, P. L. Mechanical properties of suspended graphene sheets. J. Vac. Sci. Technol. B 25, 2558-2561 (2007).

79. Lee, C., Wei, X., Kysar, J. W. \& Hone, J. Measurement of the elastic properties and intrinsic strength of monolayer graphene. Science 321, 385-388 (2008).

80. Ohta, T., Bostwick, A., Seyller, T., Horn, K. \& Rotenberg, E. Controlling the electronic structure of bilayer graphene. Science 313, 951-954 (2006).

81. Castro Neto, A. H., Guinea, F., Peres, N. M. R., Novoselov, K. S. \& Geim, A. K. The electronic properties of graphene. Rev. Mod. Phys. 81, 109-162 (2009).

82. Gómez-Navarro, C. et al. Electronic transport properties of individual chemically reduced graphene oxide sheets. Nano Lett. 7, 3499-3503 (2007).

83. Balandin, A. A. Thermal properties of graphene and nanostructured carbon materials. Nat. Mater. 10, 569-581 (2011).

84. Ferrari, A. C. \& Basko, D. M. Raman spectroscopy as a versatile tool for studying the properties of graphene. Nat. Nanotechnol. 8, 235-246 (2013).
85. Chae, H. K. et al. A route to high surface area, porosity and inclusion of large molecules in crystals. Nature 427, 523-527 (2004).

86. Stankovich, S. et al. Graphene-based composite materials. Nature 442, 282-286 (2006).

87. Stankovich, S. et al. Synthesis of graphene-based nanosheets via chemical reduction of exfoliated graphite oxide. Carbon N. Y. 45, 1558-1565 (2007).

88. Chung, C. et al. Biomedical applications of graphene and graphene oxide. Acc. Chem. Res. 46, 2211-2224 (2013).

89. Huang, Y., Liang, J. \& Chen, Y. An overview of the applications of graphenebased materials in supercapacitors. Small 8, 1805-1834 (2012).

90. Perreault, F., Fonseca de Faria, A. \& Elimelech, M. Environmental applications of graphene-based nanomaterials. Chem. Soc. Rev. 44, 5861-5896 (2015).

91. Brownson, D. A. C., Kampouris, D. K. \& Banks, C. E. An overview of graphene in energy production and storage applications. J. Power Sources 196, 4873-4885 (2011).

92. Dreyer, D. R., Park, S., Bielawski, C. W. \& Ruoff, R. S. The chemistry of graphene oxide. Chem. Soc. Rev. 39, 228-240 (2010).

93. Sreeprasad, T. S. \& Berry, V. How do the electrical properties of graphene change with its functionalization? Small 9, 341-350 (2013).

94. Suk, J. W., Piner, R. D., An, J. \& Ruoff, R. S. Mechanical properties of monolayer graphene oxide. ACS Nano 4, 6557-6564 (2010).

95. Compton, O. C. \& Nguyen, S. T. Graphene oxide, highly reduced graphene oxide, and graphene: versatile building blocks for carbon-based materials. Small $\mathbf{6}$, 711-723 (2010).

96. Hegab, H. M. \& Zou, L. Graphene oxide-assisted membranes: fabrication and potential applications in desalination and water purification. J. Membr. Sci. 484, 95-106 (2015).

97. Gahlot, S., Sharma, P. P., Gupta, H., Kulshrestha, V. \& Jha, P. K. Preparation of graphene oxide nano-composite ion-exchange membranes for desalination application. RSC Adv. 4, 24662-24670 (2014).

98. Ye, Y.-S. et al. Alkali doped polyvinyl alcohol/graphene electrolyte for direct methanol alkaline fuel cells. J. Power Sources 239, 424-432 (2013).

99. Lin, C. W. \& Lu, Y. S. Highly ordered graphene oxide paper laminated with a Nafion membrane for direct methanol fuel cells. J. Power Sources 237, 187-194 (2013).

100. Sha Wang, L. et al. Orderly sandwich-shaped graphene oxide/Nafion composite membranes for direct methanol fuel cells. J. Membr. Sci. 492, 58-66 (2015).

101. Gahlot, S., Sharma, P. P. \& Kulshrestha, V. Dramatic improvement in ionic conductivity and water desalination efficiency of SGO composite membranes. Sep. Sci. Technol. 50, 446-453 (2015).

102. Heo, Y., Im, H. \& Kim, J. The effect of sulfonated graphene oxide on Sulfonated Poly (Ether Ether Ketone) membrane for direct methanol fuel cells. J. Membr. Sci. 425-426, 11-22 (2013).

103. Jiang, Z., Zhao, X. \& Manthiram, A. Sulfonated poly(ether ether ketone) membranes with sulfonated graphene oxide fillers for direct methanol fuel cells. Int. J. Hydrog. Energy 38, 5875-5884 (2013).

104. Chua, C. K. \& Pumera, M. Chemical reduction of graphene oxide: a synthetic chemistry viewpoint. Chem. Soc. Rev. 43, 291-312 (2014).

105. Pei, S. \& Cheng, H.-M. The reduction of graphene oxide. Carbon N. Y. 50, 3210-3228 (2012).

106. Gómez-Navarro, C. et al. Atomic structure of reduced graphene oxide. Nano Lett. 10, 1144-1148 (2010).

107. Bagri, A. et al. Structural evolution during the reduction of chemically derived graphene oxide. Nat. Chem. 2, 581-587 (2010).

108. Zhang, Y., Zou, L., Wimalasiri, Y., Lee, J.-Y. \& Chun, Y. Reduced graphene oxide/ polyaniline conductive anion exchange membranes in capacitive deionisation process. Electrochim. Acta 182, 383-390 (2015).

109. Yang, J.-M. \& Wang, S.-A. Preparation of graphene-based poly(vinyl alcohol)/ chitosan nanocomposites membrane for alkaline solid electrolytes membrane. J. Membr. Sci. 477, 49-57 (2015).

110. Trewyn, B. G., Slowing, I. I., Giri, S., Chen, H.-T. \& Lin, V. S.-Y. Synthesis and functionalization of a mesoporous silica nanoparticle based on the sol-gel process and applications in controlled release. Acc. Chem. Res. 40, 846-853 (2007).

111. Kickelbick, G. in The sol gel handbook: Synthesis, characterization and applications. Vol. 1 (eds David Levy \& Marcos Zayat) 227-244 (Wiley-VCH Verlag GmbH \& Co. KGaA, 2015)

112. Chang, H., Park, J.-H. \& Jang, H. D. Flame synthesis of silica nanoparticles by adopting two-fluid nozzle spray. Colloids Surf. A 313-314, 140-144 (2008).

113. Rahman, I. A. \& Padavettan, V. Synthesis of silica nanoparticles by sol-gel: sizedependent properties, surface modification, and applications in silica-polymer nanocomposites-a review. J. Nanomater. 2012, 15 (2012).

114. Slowing, I. I., Trewyn, B. G., Giri, S. \& Lin, V. S. Y. Mesoporous silica nanoparticles for drug delivery and biosensing applications. Adv. Funct. Mater. 17, 1225-1236 (2007). 
115. Li, Z., Barnes, J. C., Bosoy, A., Stoddart, J. F. \& Zink, J. I. Mesoporous silica nanoparticles in biomedical applications. Chem. Soc. Rev. 41, 2590-2605 (2012).

116. Chen, J.-F., Ding, H.-M., Wang, J.-X. \& Shao, L. Preparation and characterization of porous hollow silica nanoparticles for drug delivery application. Biomaterials $\mathbf{2 5}$, 723-727 (2004).

117. Mihalcik, D. J. \& Lin, W. Mesoporous silica nanosphere-supported chiral ruthenium catalysts: synthesis, characterization, and asymmetric hydrogenation studies. ChemCatChem 1, 406-413 (2009).

118. Banerjee, S., Horn, A., Khatri, H. \& Sereda, G. A green one-pot multicomponent synthesis of $4 \mathrm{H}$-pyrans and polysubstituted aniline derivatives of biological, pharmacological, and optical applications using silica nanoparticles as reusable catalyst. Tetrahedron Lett. 52, 1878-1881 (2011).

119. Zou, H., Wu, S. \& Shen, J. Polymer/silica nanocomposites: preparation, characterization, properties, and applications. Chem. Rev. 108, 3893-3957 (2008).

120. Zuo, X. et al. New PVDF organic-inorganic membranes: the effect of $\mathrm{SiO}_{2}$ nanoparticles content on the transport performance of anion-exchange membranes. J. Membr. Sci. 340, 206-213 (2009).

121. Miao, J. et al. Sulfonated poly(2,6-dimethyl-1,4-phenyleneoxide)/nano silica hybrid membranes for alkali recovery via diffusion dialysis. Sep. Purif. Technol. 141, 307-313 (2015).

122. Mulmi, S. et al. Surfactant-assisted polymer electrolyte nanocomposite membranes for fuel cells. J. Membr. Sci. 344, 288-296 (2009).

123. Su, Y.-H. et al. Increases in the proton conductivity and selectivity of proton exchange membranes for direct methanol fuel cells by formation of nanocomposites having proton conducting channels. J. Power Sources 194, 206-213 (2009).

124. Su, Y.-H. et al. Proton exchange membranes modified with sulfonated silica nanoparticles for direct methanol fuel cells. J. Membr. Sci. 296, 21-28 (2007).

125. Klaysom, $C$. et al. Preparation of porous composite ion-exchange membranes for desalination application. J. Mater. Chem. 21, 7401-7409 (2011).

126. Suryani, Chang, Y.-N., Lai, J.-Y. \& Liu, Y.-L. Polybenzimidazole (PBI)-functionalized silica nanoparticles modified $\mathrm{PBI}$ nanocomposite membranes for proton exchange membranes fuel cells. J. Membr. Sci. 403-404, 1-7 (2012).

127. Madaeni, S. S., Ghaemi, N. \& Rajabi, H. in Advances in membrane technologies for water treatment: Materials, processes and applications Woodhead Publishing series in energy (eds Angelo Basile, Alfred Cassano, \& Navin Rastogi) 3-42 (Woodhead Publishing, 2015).

128. Kim, J. S. et al. Antimicrobial effects of silver nanoparticles. Nanomedicine $\mathbf{3}$, 95-101 (2007).

129. Rai, M., Yadav, A. \& Gade, A. Silver nanoparticles as a new generation of antimicrobials. Biotechnol. Adv. 27, 76-83 (2009).

130. Sawada, I. et al. Development of a hydrophilic polymer membrane containing silver nanoparticles with both organic antifouling and antibacterial properties. $J$. Membr. Sci. 387-388, 1-6 (2012).

131. Kim, J. \& Van der Bruggen, B. The use of nanoparticles in polymeric and ceramic membrane structures: review of manufacturing procedures and performance improvement for water treatment. Environ. Pollut. 158, 2335-2349 (2010).

132. Lee, S. Y. et al. Silver nanoparticles immobilized on thin film composite polyamide membrane: characterization, nanofiltration, antifouling properties. Polym. Adv. Technol. 18, 562-568 (2007).

133. Ng, L. Y., Mohammad, A. W., Leo, C. P. \& Hilal, N. Polymeric membranes incorporated with metal/metal oxide nanoparticles: a comprehensive review. Desalination 308, 15-33 (2013).

134. Liu, X. et al. Synthesis and characterization of novel antibacterial silver nanocomposite nanofiltration and forward osmosis membranes based on layer-bylayer assembly. Water Res. 47, 3081-3092 (2013).

135. Zendehnam, A., Robatmili, N., Hosseini, S. M., Arabzadegan, M. \& Madaeni, S. S. Fabrication of novel (acrylonitrile butadiene styrene/activated carbon/silver nanoparticles) heterogeneous anion exchange membrane: physico-chemical and antibacterial characteristics. J. Taiwan Inst. Chem. Eng. 44, 670-677 (2013).

136. Hosseini, S. M., Madaeni, S. S., Khodabakhshi, A. R. \& Zendehnam, A. Preparation and surface modification of PVC/SBR heterogeneous cation exchange membrane with silver nanoparticles by plasma treatment. J. Membr. Sci. 365, 438-446 (2010).

137. Palmisano, G., Augugliaro, V., Pagliaro, M. \& Palmisano, L. Photocatalysis: a promising route for 21st century organic chemistry. Chem. Commun. 3425-3437 (2007). https://doi.org/10.1039/B700395

138. Saccà, A. et al. Nafion- $\mathrm{TiO}_{2}$ hybrid membranes for medium temperature polymer electrolyte fuel cells (PEFCs). J. Power Sources 152, 16-21 (2005).

139. Zhengbang, W., Tang, H. \& Mu, P. Self-assembly of durable Nafion/ $/ \mathrm{TiO}_{2}$ nanowire electrolyte membranes for elevated-temperature PEM fuel cells. J. Membr. Sci. 369, 250-257 (2011)

140. Nonjola, P. T., Mathe, M. K. \& Modibedi, R. M. Chemical modification of polysulfone: composite anionic exchange membrane with $\mathrm{TiO}_{2}$ nanoparticles. Int. J. Hydrog. Energy 38, 5115-5121 (2013).
141. Jun, Y., Zarrin, H., Fowler, M. \& Chen, Z. Functionalized titania nanotube composite membranes for high temperature proton exchange membrane fuel cells. Int. J. Hydrog. Energy 36, 6073-6081 (2011).

142. Hosseini, S. M. et al. Electrochemical characterization of mixed matrix heterogeneous cation exchange membrane modified by aluminum oxide nanoparticles: Mono/bivalent ionic transportation. J. Taiwan Inst. Chem. Eng. 45, 1241-1248 (2014)

143. Ghaemi, N. et al. Polyethersulfone membrane enhanced with iron oxide nanoparticles for copper removal from water: application of new functionalized $\mathrm{Fe}_{3} \mathrm{O}_{4}$ nanoparticles. Chem. Eng. J. 263, 101-112 (2015).

144. $\mathrm{Xu}, \mathrm{P}$. et al. Use of iron oxide nanomaterials in wastewater treatment: a review. Sci. Total Environ. 424, 1-10 (2012).

145. Hosseini, S. M., Askari, M., Koranian, P., Madaeni, S. S. \& Moghadassi, A. R. Fabrication and electrochemical characterization of PVC based electrodialysis heterogeneous ion exchange membranes filled with $\mathrm{Fe}_{3} \mathrm{O}_{4}$ nanoparticles. J. Ind. Eng. Chem. 20, 2510-2520 (2014).

146. Ma, N., Wei, J., Liao, R. \& Tang, C. Y. Zeolite-polyamide thin film nanocomposite membranes: towards enhanced performance for forward osmosis. J. Membr. Sci. 405, 149-157 (2012).

147. Dahe, G. J., Teotia, R. S. \& Bellare, J. R. The role of zeolite nanoparticles additive on morphology, mechanical properties and performance of polysulfone hollow fiber membranes. Chem. Eng. J. 197, 398-406 (2012).

148. Kim, S. G., Hyeon, D. H., Chun, J. H., Chun, B.-H. \& Kim, S. H. Nanocomposite poly (arylene ether sulfone) reverse osmosis membrane containing functional zeolite nanoparticles for seawater desalination. J. Membr. Sci. 443, 10-18 (2013).

149. Salim, W. \& Ho, W. S. W. Recent developments on nanostructured polymerbased membranes. Curr. Opin. Chem. Eng. 8, 76-82 (2015).

150. Hosseini, S. M., Rafiei, S., Hamidi, A. R., Moghadassi, A. R. \& Madaeni, S. S. Preparation and electrochemical characterization of mixed matrix heterogeneous cation exchange membranes filled with zeolite nanoparticles: lonic transport property in desalination. Desalination 351, 138-144 (2014).

151. Curri, M. L., Comparelli, R., Cozzoli, P. D., Mascolo, G. \& Agostiano, A. Colloidal oxide nanoparticles for the photocatalytic degradation of organic dye. Mater. Sci. Eng. C 23, 285-289 (2003).

152. Wan, Q. et al. Fabrication and ethanol sensing characteristics of $\mathrm{ZnO}$ nanowire gas sensors. Appl. Phys. Lett. 84, 3654-3656 (2004).

153. Yang, Z., Li, L.-M., Wan, Q., Liu, Q.-H. \& Wang, T.-H. High-performance ethanol sensing based on an aligned assembly of $\mathrm{ZnO}$ nanorods. Sens. Actuators $B$ 135, 57-60 (2008).

154. Applerot, G. et al. Enhanced antibacterial activity of nanocrystalline $\mathrm{ZnO}$ due to increased ROS-mediated cell injury. Adv. Funct. Mater. 19, 842-852 (2009).

155. Jones, N., Ray, B., Ranjit, K. T. \& Manna, A. C. Antibacterial activity of ZnO nanoparticle suspensions on a broad spectrum of microorganisms. FEMS Microbiol. Lett. 279, 71-76 (2008).

156. Du Pasquier, A., Chen, H. \& Lu, Y. Dye sensitized solar cells using well-aligned zinc oxide nanotip arrays. Appl. Phys. Lett. 89, 253513 (2006).

157. Parvizian, F., Hosseini, S. M., Hamidi, A. R., Madaeni, S. S. \& Moghadassi, A. R. Electrochemical characterization of mixed matrix nanocomposite ion exchange membrane modified by $\mathrm{ZnO}$ nanoparticles at different electrolyte conditions "pH/concentration". J. Taiwan Inst. Chem. Eng. 45, 2878-2887 (2014).

158. Klaysom, C., Moon, S.-H., Ladewig, B. P., Lu, G. Q. M. \& Wang, L. The effects of aspect ratio of inorganic fillers on the structure and property of composite ionexchange membranes. J. Colloid Interface Sci. 363, 431-439 (2011).

159. Liu, Y.-L., Hsu, C.-Y., Su, Y.-H. \& Lai, J.-Y. Chitosan- silica complex membranes from sulfonic acid functionalized silica nanoparticles for pervaporation dehydration of ethanol- water solutions. Biomacromolecules 6, 368-373 (2005).

160. Beydaghi, $\mathrm{H}$. et al. Synthesis and characterization of new proton conducting hybrid membranes for PEM fuel cells based on poly(vinyl alcohol) and nanoporous silica containing phenyl sulfonic acid. Int. J. Hydrog. Energy $\mathbf{3 6}$ 13310-13316 (2011).

161. Liu, D., Geng, L., Fu, Y., Dai, X. \& Lü, C. Novel nanocomposite membranes based on sulfonated mesoporous silica nanoparticles modified sulfonated polyimides for direct methanol fuel cells. J. Membr. Sci. 366, 251-257 (2011).

162. Ran, J. et al. Ion exchange membranes: new developments and applications. J. Membr. Sci. 522, 267-291 (2017).

163. Chien, H.-C. et al. Sulfonated graphene oxide/Nafion composite membranes for high-performance direct methanol fuel cells. Int. J. Hydrog. Energy 38, 13792-13801 (2013).

164. Wang, L. et al. MWCNTs reinforced Nafion ${ }^{\circledast}$ membrane prepared by a novel solution-cast method for PEMFC. J. Power Sources 176, 270-275 (2008).

165. Suryani, \& Liu, Y.-L. Preparation and properties of nanocomposite membranes of polybenzimidazole/sulfonated silica nanoparticles for proton exchange membranes. J. Membr. Sci. 332, 121-128 (2009). 
166. Su, Y.-H. et al. Using silica nanoparticles for modifying sulfonated poly(phthalazinone ether ketone) membrane for direct methanol fuel cell: a significant improvement on cell performance. J. Power Sources 155, 111-117 (2006).

167. Lee, C. H. et al. Sulfonated poly(arylene ether sulfone)-silica nanocomposite membrane for direct methanol fuel cell (DMFC). J. Membr. Sci. 303, 258-266 (2007).

168. Krishnan, N. N. et al. Sulfonated poly(ether sulfone)-based silica nanocomposite membranes for high temperature polymer electrolyte fuel cell applications. Int. J. Hydrog. Energy 36, 7152-7161 (2011).

169. Yi, Z., Chaorong, C., Danying, Z. \& Hongwei, Z. Hybrid anion-exchange membranes derived from quaternized polysulfone and functionalized titanium dioxide. Electrochim. Acta 177, 128-136 (2015).

170. Miao, J. et al. Hybrid membranes from sulphonated poly (2, 6-dimethyl-1, 4phenylene oxide) and sulphonated nano silica for alkali recovery. J. Membr. Sci. 498, 201-207 (2016)

171. Kowsari, E., Zare, A. \& Ansari, V. Phosphoric acid-doped ionic liquidfunctionalized graphene oxide/sulfonated polyimide composites as proton exchange membrane. Int. J. Hydrog. Energy 40, 13964-13978 (2015).

172. Hosseini, S. M., Jeddi, F., Nemati, M., Madaeni, S. S. \& Moghadassi, A. R. Electrodialysis heterogeneous anion exchange membrane modified by PANI/ MWCNT composite nanoparticles: preparation, characterization and ionic transport property in desalination. Desalination 341, 107-114 (2014).

173. Cao, Y.-C. et al. A poly (ethylene oxide)/graphene oxide electrolyte membrane for low temperature polymer fuel cells. J. Power Sources 196, 8377-8382 (2011).

174. Joo, S. H. et al. Functionalized carbon nanotube-poly(arylene sulfone) composite membranes for direct methanol fuel cells with enhanced performance. J. Power Sources 180, 63-70 (2008).

175. Choi, B. G. et al. Enhanced transport properties in polymer electrolyte composite membranes with graphene oxide sheets. Carbon N. Y. 50, 5395-5402 (2012).
176. Lue, S. J., Pai, Y.-L., Shih, C.-M., Wu, M.-C. \& Lai, S.-M. Novel bilayer well-aligned Nafion/graphene oxide composite membranes prepared using spin coating method for direct liquid fuel cells. J. Membr. Sci. 493, 212-223 (2015).

177. Sharma, P. P. \& Kulshrestha, V. Synthesis of highly stable and high water retentive functionalized biopolymer-graphene oxide modified cation exchange membranes. RSC Adv. 5, 56498-56506 (2015).

178. Chuang, S.-W., Hsu, S. L.-C. \& Liu, Y.-H. Synthesis and properties of fluorinecontaining polybenzimidazole/silica nanocomposite membranes for proton exchange membrane fuel cells. J. Membr. Sci. 305, 353-363 (2007).

179. Klaysom, C., Moon, S.-H., Ladewig, B. P., Lu, G. M. \& Wang, L. The influence of inorganic filler particle size on composite ion-exchange membranes for desalination. J. Phys. Chem. C 115, 15124-15132 (2011).

(i) Open Access This article is licensed under a Creative Commons Attribution 4.0 International License, which permits use, sharing, adaptation, distribution and reproduction in any medium or format, as long as you give appropriate credit to the original author(s) and the source, provide a link to the Creative Commons license, and indicate if changes were made. The images or other third party material in this article are included in the article's Creative Commons license, unless indicated otherwise in a credit line to the material. If material is not included in the article's Creative Commons license and your intended use is not permitted by statutory regulation or exceeds the permitted use, you will need to obtain permission directly from the copyright holder. To view a copy of this license, visit http://creativecommons. org/licenses/by/4.0/.

(c) The Author(s) 2018 